\title{
DEFINICIÓN Y RECUPERACIÓN DE ESTRUCTURAS EN EL CASTRO DE SAN CIBRÁN DE LÁS
}

\author{
LUIS FCO. LÓPEZ GONZÁLEZ \\ MIGUEL ÁNGEL LÓPEZ MARCOS \\ YOLANDA ÁLVAREZ GONZÁLEZ
}

\begin{abstract}
Resumen
En estas líneas presentamos un breve avance de las valoraciones obtenidas de las intervenciones realizadas en recientes campañas arqueológicas en el Castro de San Cibrán de Lás (Ourense), durante el año 2000 y 2001.

Las actuaciones realizadas se centraron en la reexcavación del área ya exhumada en campañas previas para llevar a cabo una consolidación y recuperación de los restos arqueológicos que se encontraban en un claro estado de abandono. Estas actuaciones se enmarcan dentro de un proyecto más amplio que además de proponer la puesta en valor del castro de cara a su visita, pretende poner en funcionamiento un Centro de Interpretación de la Cultura Castreña donde se aportará información de los asentamientos castreños gallegos más representativos de esta cultura.

La puesta en marcha de esta iniciativa es consecuencia de la nueva demanda social y del desa-

rrollo de la propia dinámica arqueológica que han creado la posibilidad de elaborar proyectos de cara a la recuperación del patrimonio y a la rentabilidad social de estos bienes culturales. Dentro de este proyecto marco se realizó en el castro una reexcavación exclusivamente en las zonas intervenidas en actuaciones anteriores, concentradas en torno a la puerta Oeste del segundo recinto. De forma simultánea y coordinada se realizó la recuperación de estructuras identificadas durante la excavación, a base de una consolidación, restitución y adecuación de las mismas, realizada bajo la supervisión de un equipo multidisciplinar especializado en la reconstrucción arqueológica. Ofrecemos un avance de los resultados de estas intervenciones y algunas soluciones a los problemas que puede presentar la recuperación de los restos arqueológicos de cara a su puesta en valor.
\end{abstract}




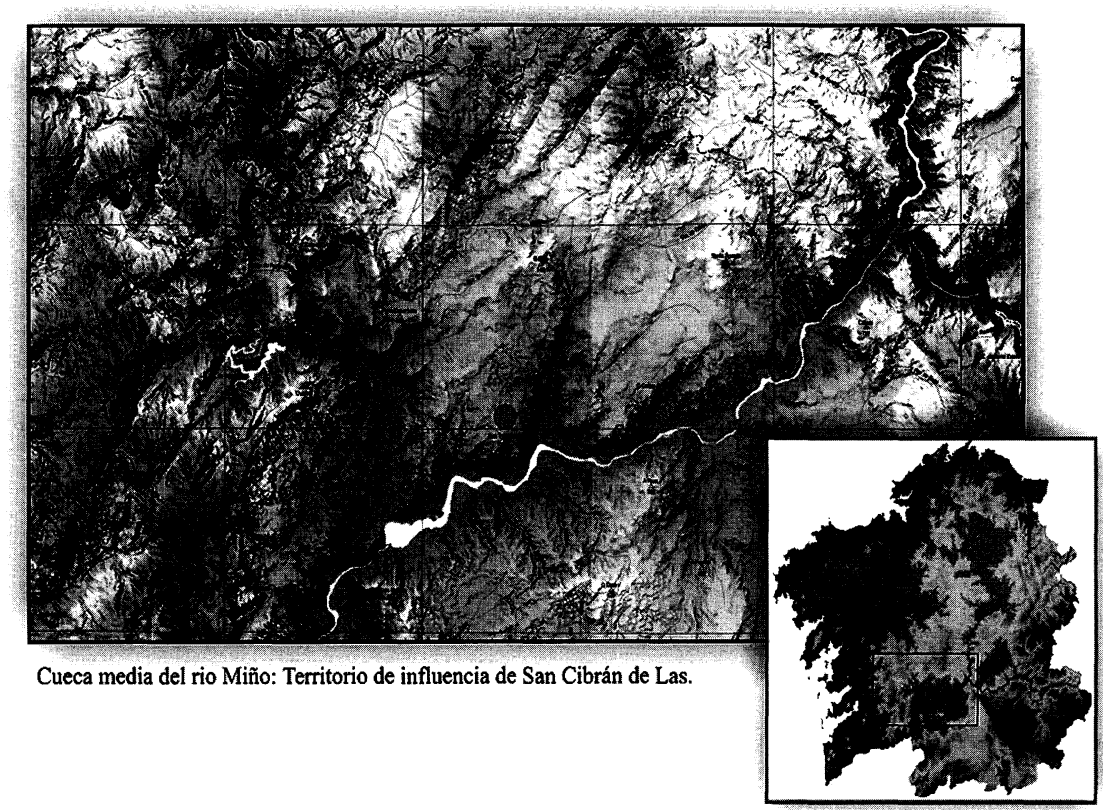

Lámina 1.- Localización geográfica de San Cibrán de Lás.

\section{LA PUESTA EN VALOR DE SAN CIBRÁN DE LÁS COMO PROYECTO DENTRO DE LA DIMENSIÓN SOCIAL DE LA ARQUEOLOGÍA}

Las actuaciones realizadas en las recientes campañas arqueológicas en el Castro de San Cibrán de Lás, en Ourense, durante los años 2000 y 2001 se centraron en la consolidación y recuperación de los restos arqueológicos de un sector muy concreto del poblado sobre el que se venían realizando campañas intermitentes de excavación desde la década de los 20 hasta los 80 , obteniendo a la vez datos de gran importancia en la investigación del yacimiento.

La idea de la puesta en valor de este yacimiento arqueológico comenzó a gestarse hace años cuando se emprendieron las primeras reconstrucciones de las murallas (1983, Bieito Pérez Outeiriño). Sin embargo es ahora cuando han coincidido una serie de circunstancias favorables para llevarlo a efecto.

1. En primer lugar, como consecuencia del desarrollo de la arqueología de gestión centrada principalmente en las labores de protección del patrimonio, se ha creado una nueva línea de actuación arqueológica encaminada a la recu- 
peración y difusión de los restos, de tal forma que en algunas comunidades es tan importante la puesta en marcha de nuevos proyectos como la recuperación del patrimonio descubierto en el pasado.

Estas intervenciones, en las que prima la conservación de los restos y la divulgación de los datos arqueológicos e históricos, pero sin dejar a un lado la investigación, se vienen realizando de forma generalizada en otros países, y en comunidades pioneras como la catalana, se han convertido en una premisa indiscutible en cualquier actuación, obteniendo esta divulgación una respuesta favorable de acogida de entre un gran sector de la población.

Siguiendo este nuevo desarrollo de los procesos de investigación, en donde la dinámica más lógica es la recuperación de la información arqueológica puesta ya al descubierto como fase previa a la apertura de nuevos frentes de actuación, han comenzado a realizarse una serie de proyectos en Galicia que reflejan esta necesidad creada por la propia dinámica arqueológica y social.

2. A esta dinámica arqueológica, se une además la creación de una demanda por parte del público en general de información cultural, demanda que antes no existía o era excepcional. De esta forma, los restos arqueológicos y la información histórica han comenzado a salir de un reducido círculo de académicos e investigadores para enfrentarse a un nuevo foro mucho más diverso y generalizado.

Los primeros en percatarse de este cambio han sido, por motivos evidentemente económicos, los sectores de servicios que dependen del turismo; lo que ha ocasionado a su vez una demanda real y una preocupación de la clase dirigente que favorece la inversión de fondos y recursos, hacia nuevos proyectos que dinamizan estos sectores.

Como consecuencia de estos dos factores expuestos, demanda social y desarrollo de la dinámica arqueológica, se han creado nuevas posibilidades para la elaboración de proyectos de cara a la recuperación del patrimonio y a la rentabilidad social de esos bienes culturales.

En este contexto general se ha consolidado en la comunidad de Galicia en estos últimos años, fomentado desde la propia Administración, y más concretamente desde el propio Servicio de Arqueología, un proyecto general de protección y difusión del patrimonio arqueológico que se plasmará en la futura Red Galega de Patrimonio. Dentro de este marco se desarrolla el Parque Arqueológico de la Cultura Castreña de San Cibrán de Lás con unos objetivos ambiciosos a largo plazo que intentarán conjugar intereses sociales y patrimoniales y que se plasmarán en la puesta en funcionamiento del futuro Centro de Interpretación como objetivo final. 
La intervención arqueológica realizada en el yacimiento en estas dos últimas campañas, es producto de una metodología desarrollada por nuestro equipo de trabajo que ha resultado ágil y eficaz para la investigación y la recuperación de los restos arqueológicos. En ella se combina la excavación, la consolidación y la restauración de forma coordinada y continua en el tiempo. No es una base de trabajo espontánea ya que la hemos puesto en práctica en los últimos años en varios yacimientos con similar problemática ${ }^{1}$ de forma que estas actuaciones garantizan resultados en todos los ámbitos, investigación, conservación y puesta en valor.

Para la puesta en valor de los restos arqueológicos se ha comenzado por la reexcavación en la zona del poblado intervenida en campañas anteriores que se venían realizando desde el año 1920 por distintos equipos. De forma simultánea se llevó a cabo la recuperación de las estructuras identificadas realizando una consolidación, restitución y adecuación de las mismas. El resultado obtenido lo expondremos en las páginas siguientes destacando soluciones a problemas concretos de recuperación de los restos y los nuevos interrogantes que surgen de la propia evolución de la intervención arqueológica.

\section{LAS CAMPAÑAS DEL AÑO 2000 Y 2001: AVANCE DE LAS VALORACIONES ARQUEOLOGÍCAS}

El interés por este yacimiento comienza con las primeras visitas de López Cuevillas en 1921 a la ciudad de San Cibrán de Lás. Florentino López Cuevillas promovió la primera intervención en 1922 continuando los trabajos hasta 1925, posteriormente las excavaciones se retomaron en 1948 y 1949 por otro investigador, D. Xaquín Lorenzo. Entre estas dos exploraciones y en los años sucesivos a las últimas campañas de 1949, el yacimiento fue intensamente expoliado y utilizado como un lugar de acopio de piedra para la construcción, de tal forma que muchas calles de la villa de Carballiño se empedraron utilizando la piedra obtenida de las ruinas del poblado, expolio que terminó en 1969 gracias a la gestión y denuncia de D. Xesús Ferro Couselo.

\footnotetext{
${ }^{1}$ Nos referimos principalmente a las actuaciones de consolidación llevadas a cabo en el Castro de Chano en los Ancares leoneses, y en el castro de Cervantes en Lugo entre otros, lamentando que posteriormente se han abandonado los restos sin mantenimiento alguno.
} 




Lámina 2.- Vuelo de los años 50 donde se aprecian las primeras intervenciones de F. López Cuevillas.

Después de un periodo de abandono de la investigación y olvido de los restos, en 1980, y a partir de una excavación de urgencia llevada a cabo en un yacimiento paleolítico («A Chaira») situado en las inmediaciones del asentamiento castreño, se retoma el interés por la investigación en este poblado. Durante los años 80 y 90 se suceden varias intervenciones en la Ciudad de San Cibrán de Lás, con una participación activa de las corporaciones municipales de San Amaro y Punxín y de la Consellería de Cultura de la Xunta de Galicia con intención de recuperar y revalorizar los restos arqueológicos.

Las primeras intervenciones sistemáticas se realizan en el 82 y 83 dirigidas por Bieito Pérez Outeiriño, y se continúan en el 87 y 88 dirigidas por F. Fariña Busto, donde participa activamente el equipo de arqueólogos de Museo Provincial de Ourense. En estos años se llevan a cabo importantes campañas de consolidación de los restos, especialmente en las puertas y las murallas y se realizan sondeos en varios puntos con el objetivo de conocer las características generales de la ciudad.

En el año 2000 se retoman de nuevo las actuaciones en el yacimiento con el objetivo de su puesta en valor. 
De cara a la planificación de la nueva excavación, nos encontramos con sectores con necesidades diferentes: en algunos puntos, en las antiguas actuaciones se había excavado hasta llegar al nivel de tierra virgen y los posibles restos estaban simplemente desaparecidos (por ejemplo en la unidad familiar $n^{0} 3$ ), mientras que en otros sectores apenas se habían descubierto las partes superiores de los muros, dejando las estructuras sin definir. El aspecto general presentaba una superficie con numerosas cuadrículas de excavación abiertas, más regulares en la zona norte donde se realizaron las actuaciones más recientes, separadas por testigos de aproximadamente un metro que impedían la visibilidad del conjunto de las estructuras, muchas de ellas derrumbadas a causa del paso del tiempo.

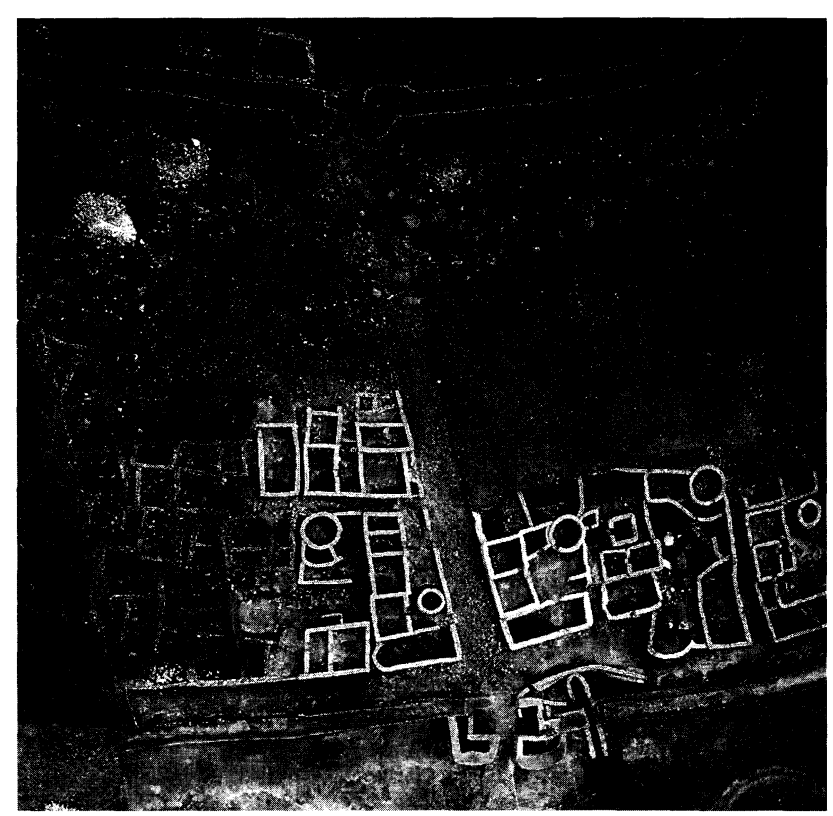

Lámina 3.- Vista parcial del sector restaurado. A la izquierda puede verse el estado de los restos antes de la restauración.

Como primera medida, antes de comenzar con las labores de consolidación de los restos era imprescindible definir el conjunto de las estructuras del poblado. Contábamos con un estudio previo de documentación bibliográfica y gráfica, pero no se conocían las características precisas de todo el sector excavado. La excavación arqueológica de las zonas intervenidas anteriormente era una cuestión básica, pues a excepción de los dos barrios que se encuentran en torno a la calle 
principal, excavados en fechas más recientes ${ }^{2}$, no se podían reconstruir las estructuras completamente.

Con este objetivo se retiraron los testigos y se excavaron las zonas en las que no se habían completado los trabajos de retirada de derrumbes y tierra, con resultados sorprendentes en algunos de los sectores. En la parte norte de la puerta Oeste se documentaron seis unidades familiares que abarcan aproximadamente 2000 metros cuadrados construidos en torno a unos 50 metros lineales de ronda, mientras que en el sector Sur se excavaron parcialmente varias unidades que se completarán en futuras campañas (2003 y 2004). La potencia arqueológica varía mucho de unos lugares a otros, por ejemplo la ronda conserva más de un metro, mientras que en el sector Sur apenas se documentan los cimientos de las estructuras.

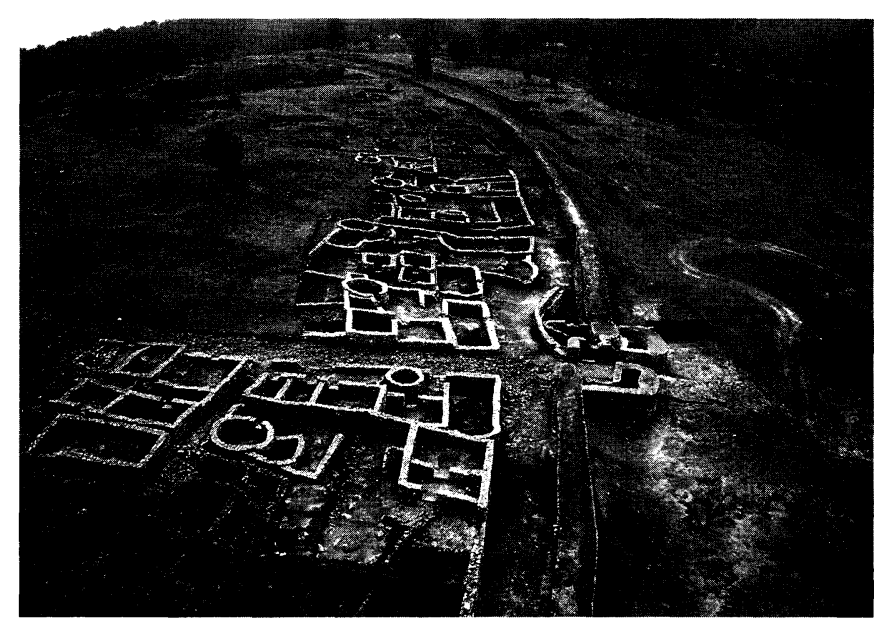

Lámina 4.- Vista general del sector excavado y consolidado después de las campañas de los años 2000 y 2001.

La «reexcavación» nos ha proporcionado numerosos datos acerca de la morfología del poblado, aunque en realidad se trata de una pequeña muestra si atendemos a las dimensiones globales del poblado, ya que pese a tratarse de una intervención de mas de 4.000 metros cuadrados éstos no llegan al 10\% de la superficie total del yacimiento, por lo que debemos advertir acerca de lo sesgado de la información obtenida hasta el momento.

\footnotetext{
${ }^{2}$ Varias campañas realizadas en los 80 y 90 por el equipo del Museo Arqueológico de Orense.
} 


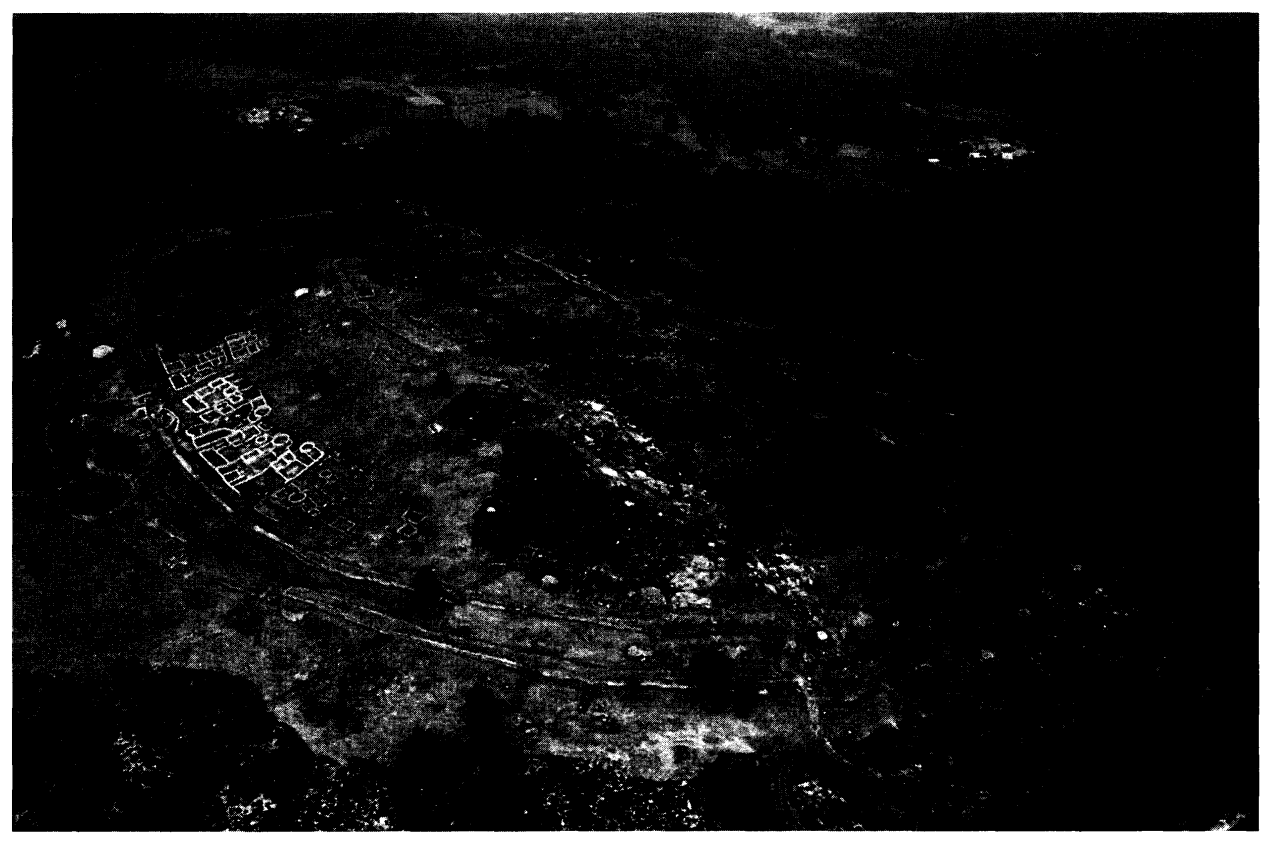

Lámina 5.- Vista general del yacimiento desde el Sur.

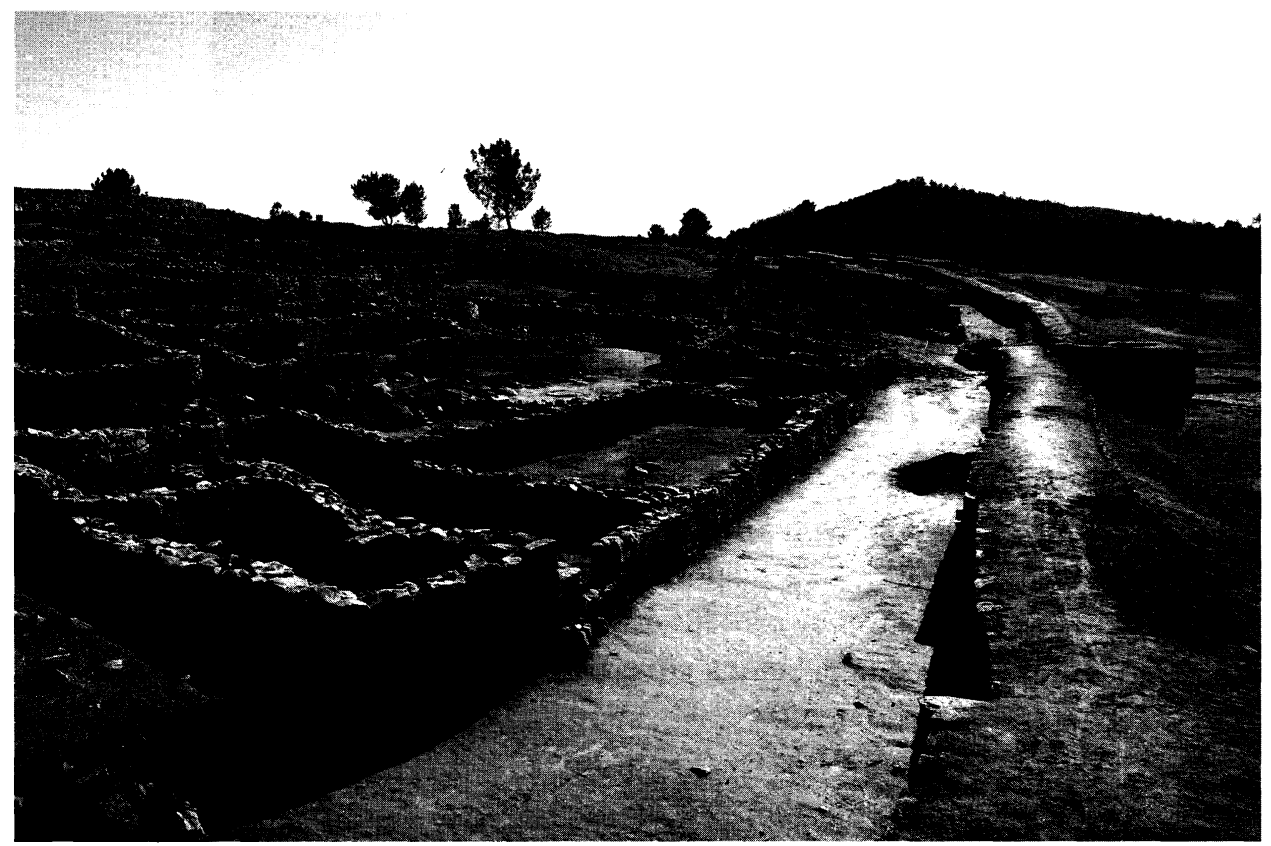

Lámina 6.- Ronda interior de la muralla una vez terminada la intervención. 
En las campañas del año 2000 y 2001 se abordó también la excavación del exterior de la muralla y de su ronda interior, abarcando el perímetro que rodea el sector del poblado afectado por las intervenciones mencionadas. Estos trabajos implicaban la definición del área ocupada por el aljibe que se inserta en la muralla en un punto casi adosado al torreón sur de la puerta Oeste.

Como resultado de las labores de excavación realizadas en estas campañas se pudieron conocer las dimensiones reales de la ronda interior que se abre de forma bastante regular a lo largo del perímetro de la muralla. Esta ronda permitía una comunicación interior desde la puerta hacia ambos lados del poblado y a su vez enlazaba con una serie de calles perpendiculares que se abren entre las distintas unidades familiares a la vez que permitía el acceso a la parte superior de la muralla a través de escaleras que se suceden a lo largo de todo el tramo.

La intervención también ha permitido documentar como todo el sector construido en torno al aljibe (nos referimos tanto a las viviendas $n^{\circ} 1$ y 2 , los torreones, la muralla y el acceso de la Puerta Oeste) han sido construidos en un mismo momento, siguiendo un mismo plan de urbanización que respetó un elemento público importante que es el acceso al aljibe ${ }^{3}$. Esta necesidad condicionó la inflexión de la ronda en este punto y el retranqueo de la superficie dedicada a vivienda.

La estructura que conforma el aljibe consta de un depósito que conservaba en los años 20 cinco metros de altura y posiblemente estuviera rematada en la parte superior por una bóveda de aproximación de hiladas que se perdió ${ }^{4}$. Tenía un aliviadero que atravesaba la muralla y permitía salir hacia el exterior el caudal sobrante del manantial. En el sondeo realizado en esta zona exterior del aljibe pudimos documentar como el foso en este sector fue excavado después de la construcción del rebosadero de la fuente pues a esta estructura se asocian niveles horizontales que son cortados por el foso.

Es de suponer también que existan otros puntos de aprovisionamiento de agua en el poblado si tenemos en cuenta sus grandes dimensiones.

Como dato novedoso hemos documentado como el foso sirvió además de cantera para extraer piedra para la construcción del poblado, destacando que el granito

\footnotetext{
${ }^{3}$ En la parte interior de la muralla, el acceso al aljibe se realizaba por medio de unas escaleras construidas en piedra que continuaban hasta el fondo del aljibe de modo que permitían el acceso independientemente de la profundidad del depósito. Una vez excavado el sector en su totalidad nos ha permitido saber que el acceso al depósito de agua se hacia desde los dos lados, aunque debido a las antiguas consolidaciones y a la perdida de hiladas en el paramento del lado sur del depósito, no se conserva el enlace del acceso a la fuente por este lado.

${ }^{4}$ LÓPEZ CUEVILLAS, F. A citania do monte A Cibdade en San Cibrao das Lás. Boletín de la Real Academia Gallega, XVII, 1927-28 (1-9 e 51-57).
} 
del foso, de peor calidad, se utilizó de forma general para levantar las viviendas, mientras que en la construcción de otras estructuras de mayor entidad y referencia visual como los torreones, se utilizó un granito de mejor calidad y de tonalidad más clara. Las excavaciones realizadas en los tramos de muralla del sector Oeste nos han permitido documentar que el paramento de tipo helicoidal no se extiende a todo su trazado, más bien es bastante excepcional, por lo que la construcción de la muralla debió ser más ágil de lo que se pensó en un principio.

\section{Las viviendas}

Conocíamos a partir de las excavaciones más antiguas que las estructuras se articulan en torno a una calle principal que desde la entrada Oeste del yacimiento permite acceder al recinto superior. En las publicaciones más recientes ${ }^{5}$ se menciona la existencia en el poblado de casas-patio, pues las dependencias parecían articularse en torno a una estancia grande sin posibilidad de cubrición. En este sentido la nueva intervención apunta la existencia de agrupaciones de estructuras que conformaban grupos o barrios distribuidos en torno a calles o zonas de paso abiertas, de forma tanto transversal como perpendicular a la muralla, por otra parte se definió con detalle su ubicación y sus procesos de construcción como veremos a continuación.

Dentro de estos grupos de cabañas o estructuras, hemos podido distinguir varias unidades familiares. Llamamos unidades familiares al espacio que ocupa físicamente un grupo familiar dentro del poblado. Esta unidad básica de ocupación estaría formada por distintas estructuras agrupadas que comparten muros medianeros y espacios de acceso comunes separándose de otras unidades por calellos y muros, de forma que las construcciones de una unidad familiar no compartirían muros principales de sus estructuras con ninguna otra. Esta delimitación física de un espacio familiar frente a otro es reflejo del deseo de independencia espacial y de autonomía entre las distintas familias.

La existencia de esta independencia familiar en la ocupación del espacio habitable del poblado se documenta en la mayoría de los asentamientos castreños, forma parte de su tradición como reflejo del carácter independiente no solo del grupo familiar sino de la comunidad que habita cada castro. Sin embargo, en el caso del poblado de San Cibrán de Lás, esta tradicional forma de construir tiene ciertos matices que implican una actuación de la comunidad distinta a la hora de fundar el poblado: nos referimos a la existencia de parcelaciones previas a la construcción.

${ }^{5}$ RODRÍGUEZ CAO, C., XUSTO RODRÍGUEZ, M. FARIÑA BUSTO, F. A cidade San Cibrán de Lás. Colección guías do patrimonio cultural IV, Caixa Galicia, 1992.

Cuadernos de Estudios Gallegos, Tomo LI, Fascículo 117, Santiago 2004. (Págs. 79 - 113) 


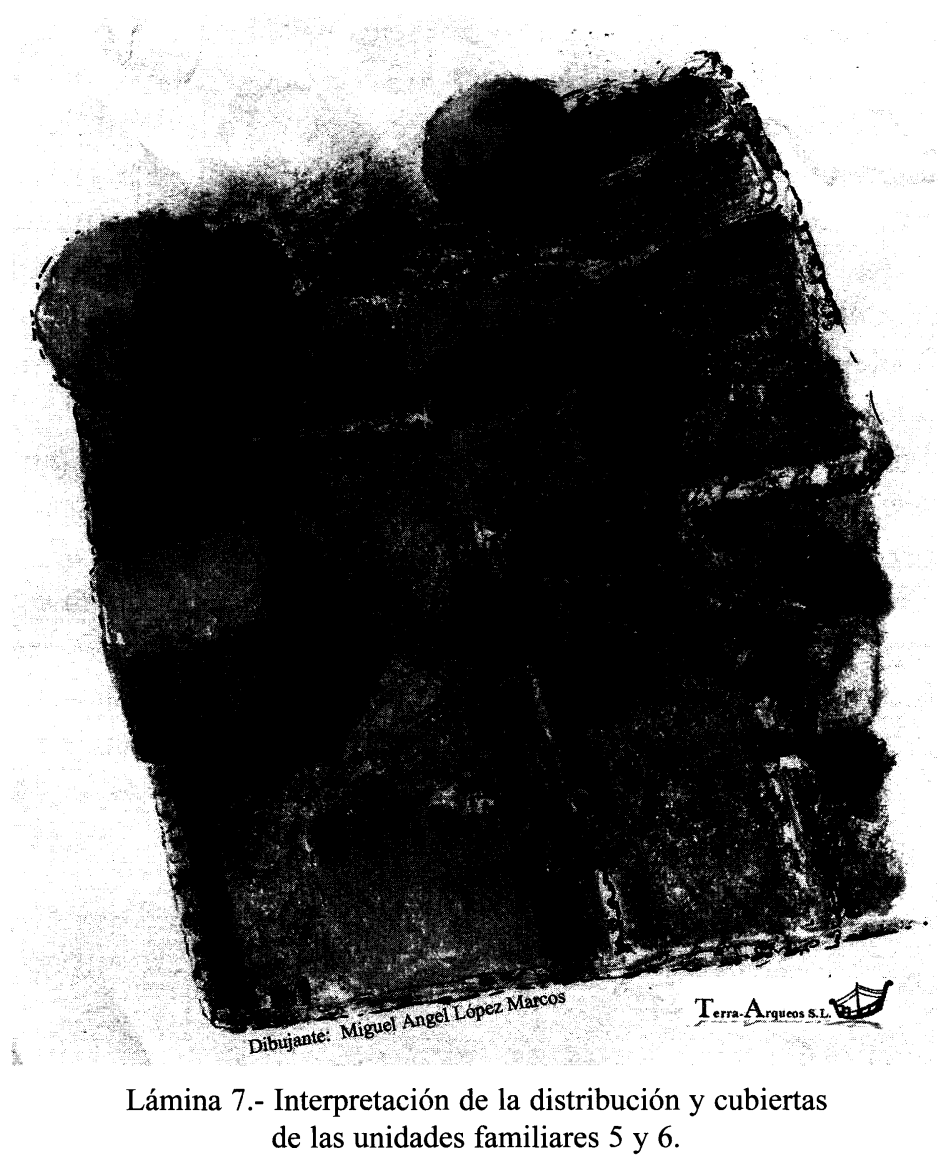

Durante la excavación realizada en estas últimas campañas hemos podido comprobar que formando la base de las estructuras que definen las distintas unidades familiares, existen unos muros construidos de forma previa que se extienden a lo largo del perímetro exterior de la unidad. Estos «muros maestros» delimitan un espacio o parcela y se construyen antes que las dependencias, levantándose después sobre ellos los paramentos que configuran la vivienda. Existe por tanto una parcelación del terreno previa a la edificación: antes de la construcción propiamente dicha se había trazado un límite que dividía la parcela de superficie que iba a ocupar cada grupo familiar, y a la vez se acondicionó la ladera diseñando aterrazamientos para conseguir superficie habitable. En el sector sur excavado al interior de la Puerta Oeste es donde mejor se conserva esta distribución de tierras, configurando cada una de las unidades un espacio bastante regular en cuanto a medidas que ronda los 220-260 metros cuadrados. 
Posteriormente estos primeros muros de escaso alzado se amortizan en algunos sectores y sobre ellos se continúan levantando las estructuras. Este hecho nos lleva a pensar en la existencia de un reparto de parcelas previo a la construcción de cada unidad familiar aunque desconocemos cómo y quién decidía ese reparto. A pesar de no poder responder a estos interrogantes, la existencia de una planificación y un reparto de parcelas, son ideas que caminan acordes con la hipótesis de la aparición de las citanias como desarrollo de las comunidades castreñas hacia una sociedad más compleja (sin que por ello deje de ser igualitaria respecto al acceso a los recursos), como ocurre en otras culturas indígenas de la Península.

De igual modo pudimos comprobar la existencia de posteriores particiones de estas parcelas, reflejo de la evolución sufrida en el poblado a lo largo del tiempo, fruto del paso de varias generaciones y sus cesiones o herencias.

La superficie que ocupa cada unidad en el sector Sur del poblado es muy similar a excepción de las unidades que han sufrido reformas y han sido adaptadas a nuevas divisiones o ampliaciones internas que ocupan más o menos suelo. Dentro de cada una se reparte el espacio interior de forma arbitraria aunque en todas se documenta la existencia de un patio al que se abren las demás dependencias.

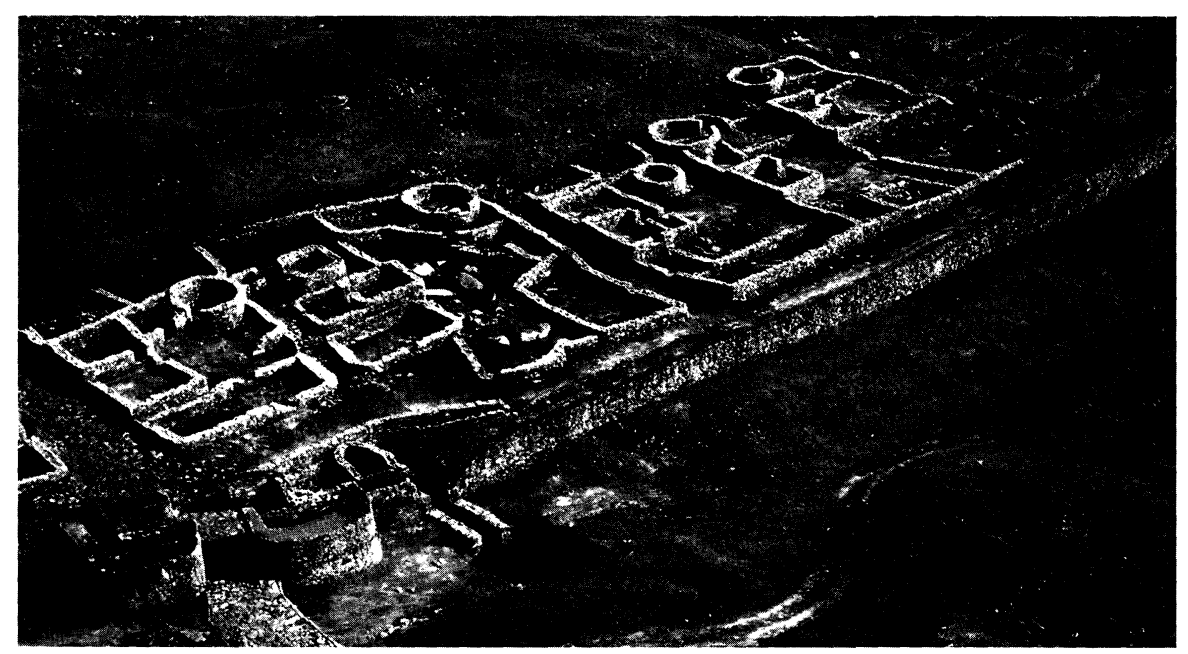

Lámina 8.- Unidades familiares excavadas en el sector Sur de la Puerta Oeste.

Las estructuras que formaban parte de cada vivienda son, como hemos dicho en cada caso, distintas y cada familia divide su espacio según sus necesidades, aunque existen dependencias con funcionalidades explícitas que siempre aparecen: 
- Una dependencia se dedica a cocina, conserva siempre los restos de un hogar, acompañado indistintamente por hornos, parrillas, alacenas y abundantes restos de material de cocina. El número de éstas depende del tamaño de grupo familiar que alberga cada unidad de ocupación. En torno a esta dependencia que suele construirse en primer lugar, se ubican unas áreas complementarias igualmente de carácter doméstico a modo de pequeños alpendres o bien zonas exteriores que sirven para complementar dichas funciones. A estas dependencias se adosan otras habitaciones dedicadas a otras funciones ${ }^{6}$.

- Una, o varias construcciones dedicadas a zonas auxiliares de trabajo doméstico, normalmente asociadas al área entorno a la cocina como hemos dicho anteriormente, que conservan restos de materiales muy diversos y que en algunos casos se abrían al patio directamente a modo de porches o alpendres.

- Una de las construcciones suele ser utilizada como almacén. Son de menor tamaño, de forma circular o cuadrangular, algunas veces exentas y con una solera mejor acondicionada, situada, al igual que su acceso, a una mayor altura. Sus condiciones de aislamiento del exterior se tienen muy en cuenta en su construcción.

- Una estancia también muy cuidada en ocasiones enlosada o empedrada, de mayor tamaño y en algunos casos calefactada.

Una cuestión importante a la hora de distribuir el espacio y construir, es la que se refiere a las soluciones que adoptan para corregir el efecto de los aportes de aguas, ya que la propia morfología del terreno, teniendo en cuenta que se sitúan en una ladera aterrazada, complica la evacuación del agua de escorrentía. Pensando también en estos condicionantes se configura la disposición de las distintas dependencias en función de una correcta evacuación del agua lo que define en cierto modo el tipo de cubierta (cónica, a una, dos o cuatro aguas), realizada siempre con elementos vegetales. La distribución de las diferentes vertientes de los tejados está sujeta a un cuidadoso reparto del agua tanto para su aprovechamiento como para su correcta evacuación. En este sentido se han documentado la existencia de des-

\footnotetext{
${ }^{6}$ Respecto a la distribución de los elementos ergológicos prescindiremos en este trabajo de su valoración apuntando únicamente el hecho de que la gran mayoría de la cerámica es de tradición indígena, con formas y motivos castreños.
} 


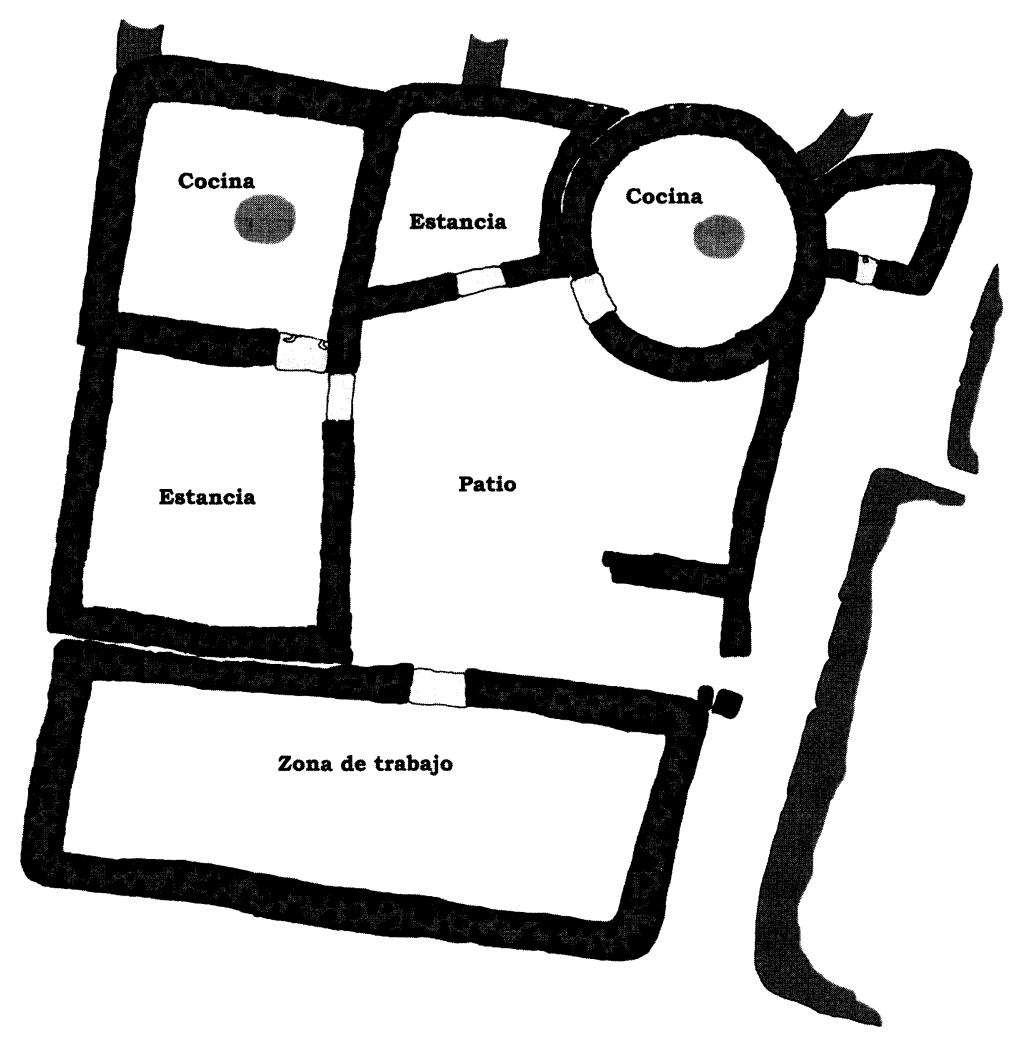

Lámina 9.- Funcionalidades de las dependencias de la unidad 1.

agües localizados en los paramentos situados en la parte más baja de las unidades que van a dar a la ronda interior. También en algunos casos se canaliza el agua de escorrentía como ocurre en la zona de paso entre la unidad $n^{\circ} 1$ y n $^{\circ} 2$, o se forman pequeños diques en los laterales de las calles para evitar que el agua que discurre siguiendo la pendiente pueda entrar en las dependencias o generar cárcavas en las soleras. Las distintas soluciones al problema del agua nos permiten poder reconstruir en muchos casos como eran las cubiertas y tener una imagen más aproximada de cómo fue el poblado.

En algunos puntos de la zona excavada se han descubierto reestructuraciones de las unidades de ocupación que indican que con el paso del tiempo y el desarrolo de los grupos familiares, las viviendas sufrían reformas para adaptarse a nuevas necesidades. En algunos lugares simplemente se han cambiado muros o divisio- 


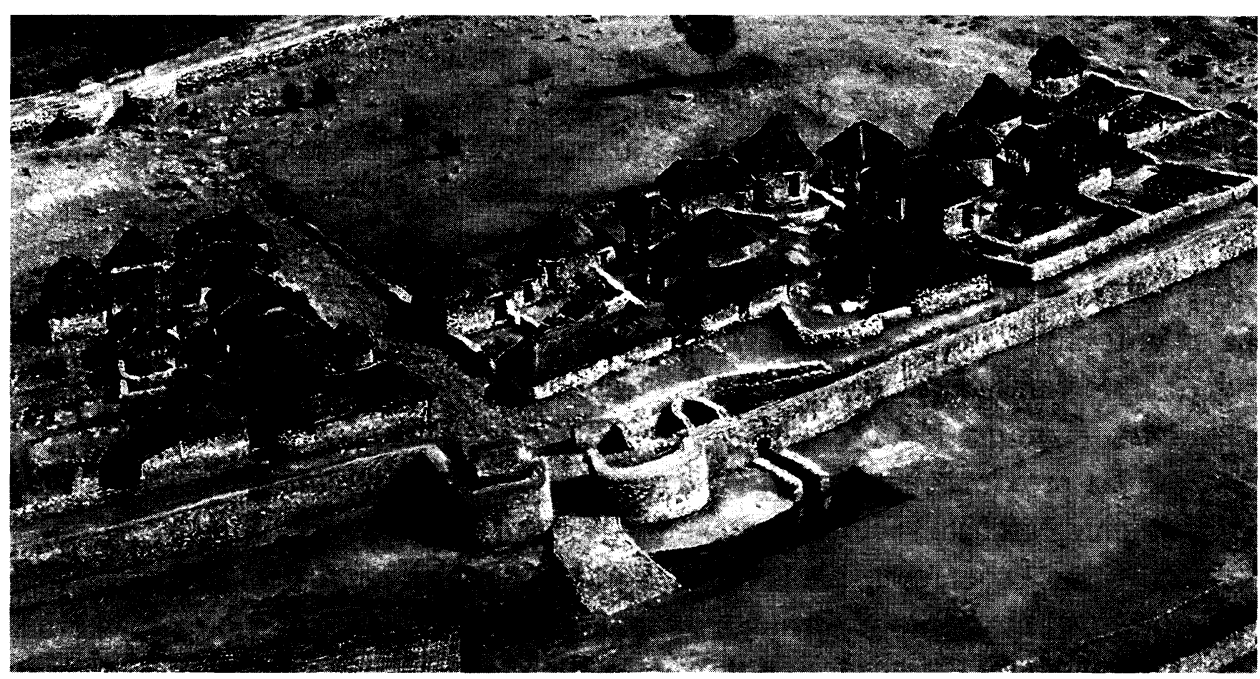

Lámina 10.- Reconstrucción hipotética de las cubiertas castreñas.

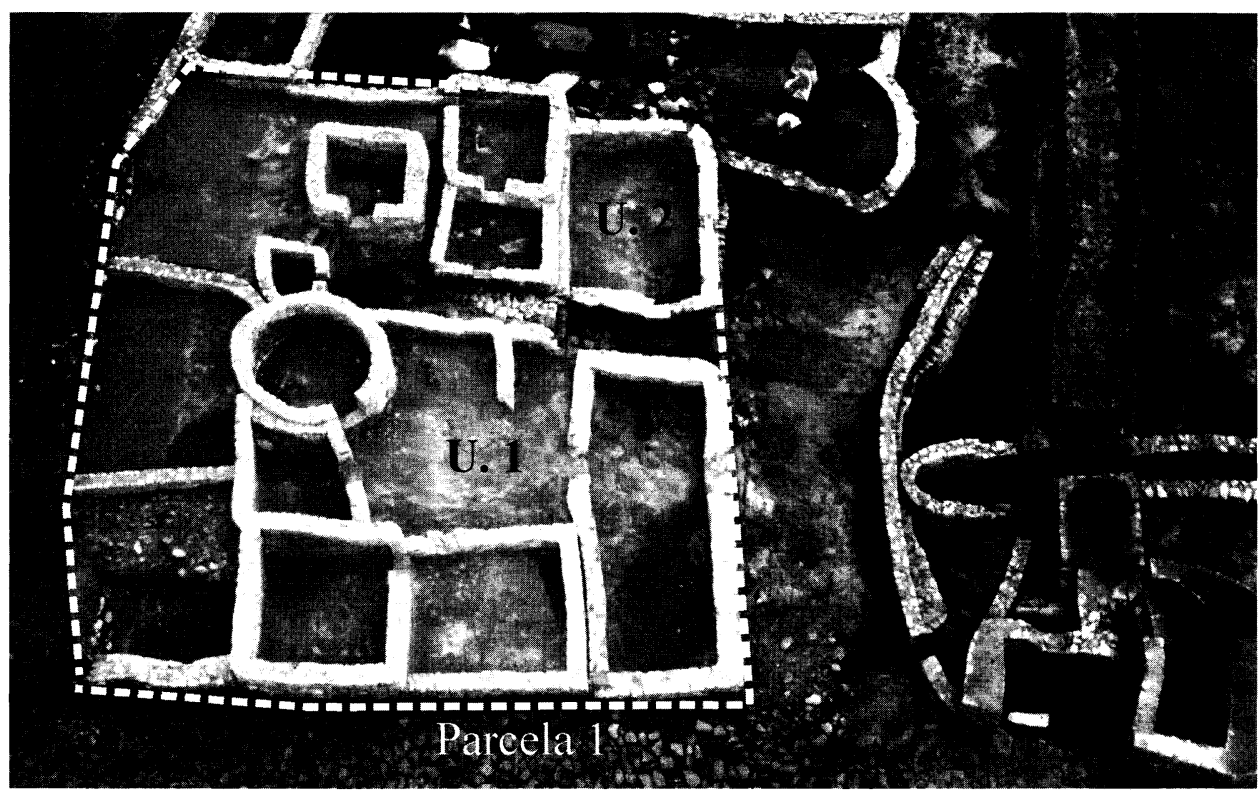

Lámina 11.- Parcela $\mathrm{n}^{\circ} 1$, posteriormente dividida en dos unidades familiares. 
nes, pero en otros, como en el caso de la unidad $\mathrm{n}^{\circ} 11$ se ha realizado una gran transformación del espacio. En esta unidad aparecen dos niveles distintos de ocupación producto de las reformas: se aprecia la eliminación de varias construcciones sobre los que se levantó una casa cuadrangular hecha con piedras reaprovechadas (pueden verse las tallas de las piedras al interior) y que de forma excepcional tiene un acceso exterior hacia un piso superior. Este tipo de remodelaciones como ya hemos apuntado con anterioridad son fruto de una reestructuración de parcelas y un claro indicio de cesiones o herencias de terreno. Otro ejemplo claro de estos procesos es el caso de las viviendas que llamamos Unidad 1 y 2 , en donde puede apreciarse la transformación de una única vivienda en dos unidades más pequeñas. (Lámina 11).

Para las próximas campañas de excavación, además de completar la información obtenida en este sector del poblado (Sector Oeste) se ha proyectado sondear nuevas zonas. Esperamos que las futuras intervenciones confirmen los datos obtenidos hasta el momento y permitan conocer otros nuevos que solucionen los muchos interrogantes planteados como son, el momento de la fundación del poblado y su abandono, el origen de la población que lo ocupó y los motivos que llevaron a planificar la construcción de este castro que aglutina varias comunidades indígenas como sugiere su tamaño y su implicación en las transformaciones que en torno al cambio de era provoca la conquista romana.

\section{LA RECUPERACIÓN DE LOS RESTOS: PROBLEMAS Y RESULTADOS}

Como hemos dicho al comienzo en el año 2000 se retoman de nuevo las actuaciones en el yacimiento con el objetivo de su puesta en valor. Con este propósito se propone una tarea fundamental antes de comenzar cualquier nueva labor de investigación: recuperar los restos arqueológicos ya exhumados en campañas anteriores, que se encuentran en estado de abandono.

La intervención no solo debía romper con las pautas marcadas en tratamientos anteriores, sino que debía establecer un modelo totalmente nuevo en el cual se integraran las antiguas restauraciones aplicadas al yacimiento ${ }^{7}$.

\footnotetext{
${ }^{7} \mathrm{Su}$ base era el recrecido de varias hiladas de piedra con relleno de piedras irregulares sujetas bien con cemento, o a hueso dependiendo de la intervención. En las intervenciones mas recientes se separaba el lienzo original del nuevo mediante la colocación pequeñas láminas de pizarra cada 50 $\mathrm{cm}$, mientras que en consolidaciones anteriores realizadas en sectores muy puntuales, como es el caso de los lienzos de la muralla, esta diferenciación no se hizo.
}

Cuadernos de Estudios Gallegos, Tomo LI, Fascículo 117, Santiago 2004. (Págs. 79 - 113) 
Obviando la exhibición de la ruina tal y como aparece tras su excavación, que aparte de una connotación romántica, estaría condenando a los restos a una alteración progresiva y un deterioro constante, la consolidación de las estructuras con un programa de mantenimiento se presenta como lo más idóneo. Si además se pretende una exposición didáctica y en definitiva una difusión cultural basada en la puesta en valor de los restos, es imprescindible pensar en la reconstrucción o la restitución de elementos y en la creación de vías de información con diferentes niveles.

La intervención en San Cibrán de Lás cuyo objetivo final es la puesta en valor y difusión de los restos arqueológicos, necesitaba de la creación de un modelo específico a la hora de tratar los restos, por lo que se diseñó una estrategia general partiendo de una unificación de criterios, supeditada a las características del yacimiento y a la finalidad última de la intervención.

Este plan general de actuación por tanto pretende ser coherente y resolutivo de cara a unificar el método utilizado en todo el yacimiento. Todo ello bajo una uniformidad en el tratamiento de los restos, sin olvidar los criterios de intervención vigentes en restauración para la consolidación y restauración de yacimientos arqueológicos.

La creación de este plan general de actuación para la conservación y la difusión del yacimiento arqueológico de San Cibrán de Lás está marcada por el propio proceso de excavación, la documentación que de él se obtiene, el estado de conservación de las estructuras y el estudio de los procesos de alteración previsibles, que determinaran en gran medida la dirección a seguir.

La pretensión última es que a través de los restos se consiga un discurso coherente de cara a la difusión y comprensión de los mismos, y por otra parte se garantice su conservación. Estos objetivos están supeditados a la profundidad y la extensión de la restauración de las estructuras definidas durante la reciente excavación arqueológica y el resto de estructuras documentadas en las anteriores campañas ${ }^{8}$. Partiendo de la base que se trata de una intervención en la que se realizan al mismo tiempo trabajos de excavación y consolidación, nunca se puede hasta el último momento tener la certeza de los límites de la propia intervención.

Desgraciadamente la combinación de estas dos actividades no suele ser habitual, en muchos casos ni siquiera se contempla la necesidad de realizarlos de modo

\footnotetext{
${ }^{8}$ No hay que olvidar que $A$ Cidade de San Cibrán de Lás fue objeto de ciertas consolidaciones y restauraciones en campañas precedentes. Se actuó en las campañas del 2000 y 2001 sobre un total de $3.900 \mathrm{~m}^{2}$ afectados por diversos agentes externos, y con un grado de alteración muy diverso.
} 
consecutivo e inmediato. La aplicación concreta de esta combinación en San Cibrán de Lás viene a agilizar y desarrollar la capacidad de registro de tal modo que los trabajos de restauración pueden realizarse una vez finalizado el registro arqueológico de forma inminente, y por lo tanto los restos apenas sufren procesos de alteración.

Prácticamente en toda la extensión de la zona excavada se ha podido registrar con certeza la disposición y morfología de las diferentes estructuras, y son excepcionales los casos en que los datos obtenidos no permiten con total fiabilidad su reconstrucción ni solucionan la interpretación de ciertas estructuras y el funcionamiento completo del espacio que describen.

El grado de intervención que se plantea pretende ser lo más homogéneo posible; hay estructuras en las que sólo se podrá marcar unas pautas generales que deben tender, únicamente a su conservación para permitir una intervención respetuosa posterior. Por otra parte la interpretación de la ruina, puede dar lugar a una intervención más profunda tendente a mejorar su interpretación para potenciar la función didáctica de su exposición. En cualquier caso, se plantean actuaciones definidas junto a otras susceptibles de sufrir modificaciones según se desarrolla la excavación y la interpretación del yacimiento.

\section{Los Criterios de intervención}

Los criterios o directrices que cimentan la base del plan general de actuación evidentemente se integran en el ámbito de las técnicas y criterios vigentes en la restauración A la hora de determinar el tratamiento que se aplica a las diferentes estructuras recuperadas en el yacimiento se tuvo muy en cuenta una serie de criterios que en definitiva marcaron la pauta de la intervención. Se refieren fundamentalmente al porcentaje de reconstrucción de la ruina, las técnicas empleados y a la reversibilidad de los materiales

La decisión del porcentaje de reconstrucción de los restos deriva directamente de los datos perfilados en la primera campaña una vez que se definieron las estructuras arqueológicas tras su excavación. Se pudo comprobar la intencionalidad urbanística para al menos este sector del yacimiento. Una vez que los constructores dividían las distintas parcelas, se iniciaba la construcción de una estancia principal a la que se iban agregando construcciones de distinta entidad, tamaño y forma. Siguiendo este proceso, y teniendo en cuenta la gran extensión restaurada en el yacimiento, en donde se configura una superficie de estructuras con un aspecto guillotinado, en la recuperación de volúmenes se decidió dar mayor resalte a las estancias construidas en primer lugar en detrimento de las que poseen un carácter secundario o se adosan a las anteriores. 
Partiendo de la base de que «La reintegración ha de ser la parte de un todo y nunca el todo de una parte», la relación entre el volumen de la reintegración y el del original conservado, sufre una variación en lo referente al porcentaje de la restitución, fundamentalmente atendiendo a dos cuestiones: a) la función didáctica que se quiere conseguir, (para lo que se evita el aspecto guillotinado de los restos y se juega con los volúmenes de estructuras en relación a la diferenciación de estancias) y b) las propias necesidades implicadas en su conservación.

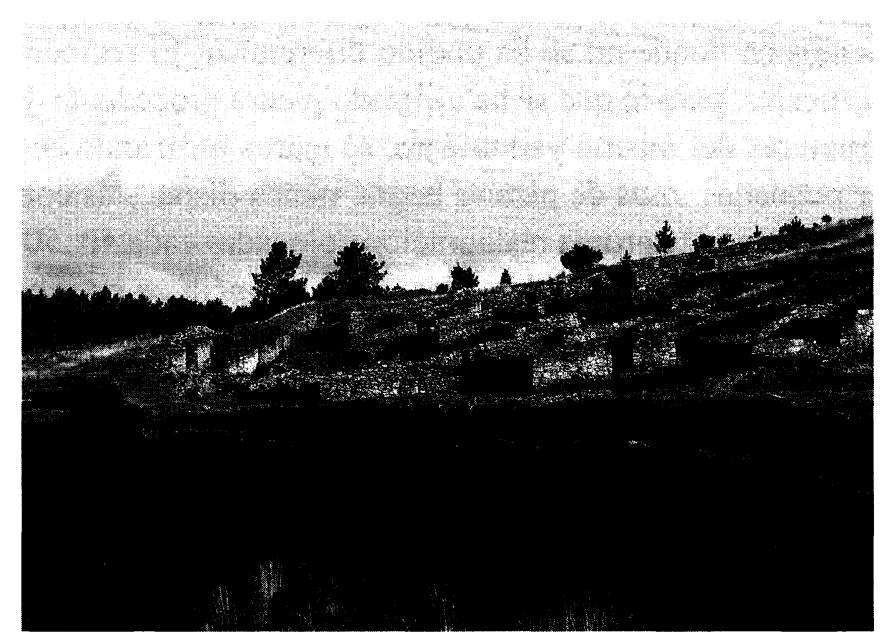

Lámina 12.- Aspecto final del volumen aquirido por los restos una vez finalizada la intervención.

En lo referente a las técnicas empleadas y a la reversibilidad de los materiales, $s e$ han tenido en cuenta siempre como primera medida en la restauración de las estructuras, que los materiales utilizados necesariamente cumplan dos requisitos, por un lado su posibilidad de deshacerse y reconstruirse estas intervenciones en un momento posterior y por otra su durabilidad en el tiempo, garantizando una perduración adecuada de la consolidación de cara a su puesta en valor para el público.

Debemos tener en cuenta que se trata de un yacimiento situado en un entorno con un clima poco propicio para la perdurabilidad de los materiales aplicados, que puede demandar igualmente tratamientos profundos con una reversibilidad relativa. La elección adecuada de las argamasas utilizadas para este caso concreto, en función de lo expuesto es imprescindible para garantizar la eficacia de la intervención y su reversibilidad relativa es exclusivamente mecánica; la utilización de capas de intervención contribuye a mejorar los índices de reversibilidad. 
En cualquier caso también hay que dejar claro que una intervención realizada inmediatamente después de una documentación exhaustiva no debe plantear modificaciones significativas y, por lo tanto, la importancia del grado de reversibilidad de los productos empleados es mucho menor.

Otros criterios básicos aplicados: La diferenciación entre elementos originales y restituidos y la distinción de las diferentes fases

La diferenciación entre elementos originales y elementos restituidos no siempre es posible en restauración. En el caso concreto de San Cibrán de Lás son mínimos los elementos en donde no se ha podido diferenciar. El recrecimiento de los paramentos verticales, para lo que se ha utilizado piedra procedente de los derrumbes de las estructuras del mismo yacimiento, se marca utilizando como elemento diferenciador pequeñas losas de pizarra negra, nunca dispuestas como línea continua sino alternadas con la propia restauración colocadas cada $40,50 \mathrm{~cm}$, entre las hiladas originales y las reconstruidas. Con esta distancia se pretende separar lo restaurado del original sin crear un elemento diferenciador entre los dos paramentos que rompa el conjunto arqueológico y sin deteriorar la comprensión del volumen de reconstrucción de estas estructuras.

Respeto a la distinción de las diferentes fases existentes, en San Cibrán de Lás se dan varias etapas constructivas, se pretende mostrar las más importantes realzando las más significativas a la hora de acometer los tratamientos de conservación, restauración y reconstrucción, siempre determinado por las directrices generales de la valoración arqueológica.

\section{Estado de conservación de las estructuras y procesos de alteración}

No sólo hemos de tener en cuenta el estado de conservación actual de los diferentes elementos presentes en el yacimiento, sino que se han analizado los procesos de alteración que influyen a corto o a largo plazo en su conservación de los mismos para, y a partir de ahí establecer los tratamientos más idóneos para conseguir la conservación mas apropiada.

Los principales problemas con que nos encontramos a la hora de abordar la restauración fueron los problemas estructurales junto otros de menor envergadura como la proliferación de biofitos, el agua y la acción antrópica, sin olvidar en el caso de los perfiles, las condiciones físicas del terreno y la presencia de animales, especialmente lepóridos. En general, son los problemas estructurales los que más merecen nuestra atención, puesto que suponen el mayor riesgo para una futura conservación. 
Los procesos de alteración de los paramentos verticales están relacionados con su estabilidad frente a un posible derrumbe, con la alteración de sus cabeceras y con la proliferación de vegetación. El desplome sobre la vertical suele ser importante dependiendo fundamentalmente de la disposición con relación a la pendiente y de la altura del muro conservado. En el yacimiento arqueológico nos encontramos con paramentos de alturas muy variadas que van desde 30 ó $40 \mathrm{~cm}$ a más de $2 \mathrm{~m}$.

Por otra parte no hay que olvidar que estamos tratando restos de excavaciones recientes, y estructuras exhumadas en campañas anteriores en donde la alteración de las cabeceras es evidente en todas aquellas zonas en las que no se han llevado a cabo tratamientos puntuales anteriores. El desplazamiento y la ausencia desigual de las piedras exteriores y del relleno van en detrimento de la interpretación visual de las estructuras y de su conservación; la presencia de piedras sueltas conlleva el derrumbe paulatino de las siguientes hiladas y la penetración de agua de lluvia que arrastra las argamasas y, que junto con la humedad por capilaridad, favorece el crecimiento de plantas cuyas raíces también contribuyen a su deterioro. La proliferación de diversos tipos de biofitos, son parte responsable de graves deficiencias que son difíciles de atajar en según que casos. Cuando los biofitos carecen de estructura leñosa no presentan grandes problemas, dado que se puede resolver el problema tanto manualmente como con herbicidas que se presentan en el mercado, mayormente de tipo hormonal.

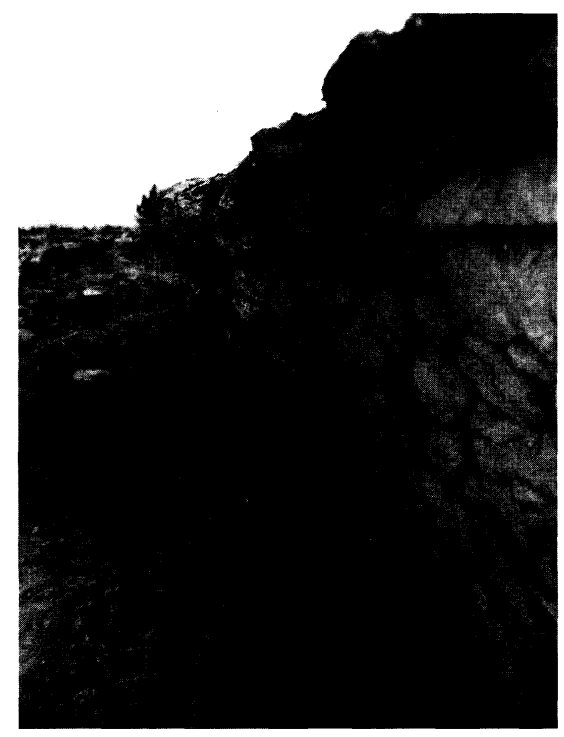

Lámina 13. Muro de la Unidad 1, se puede apreciar su desplome sobre la vertical. 
Si tenemos en cuenta el proceso de degradación del yacimiento de San Cibrán de Lás y la disposición de los muros perpendiculares a la ladera, como se ve en el dibujo adjunto (Lámina 15), podemos observar que la evolución tras la destrucción se complica en la tercera fase debido a su peculiar disposición en pendiente. Es el peso excesivo de un relleno en la vivienda el que presiona sobre el muro inferior que no soporta más de $100 \mathrm{~kg} / \mathrm{cm}^{2}$ a la rotura por flexión. Las líneas de actuación en este sentido se reflejan en el cuarto dibujo donde se ha excavado la estancia. Se consigue con ello tras la documentación el aligeramiento estructural de entre 30 y 70 toneladas métricas de relleno.

Todo esto beneficia en gran medida a la futura conservación de la estructura o estancia, sin embargo debe completarse con la restauración de unos paramentos ya debilitados. En ocasiones se emplean entibaciones para concluir la excavación sin que exista peligro de derrumbe. Tras dicha operación se procede en su caso al
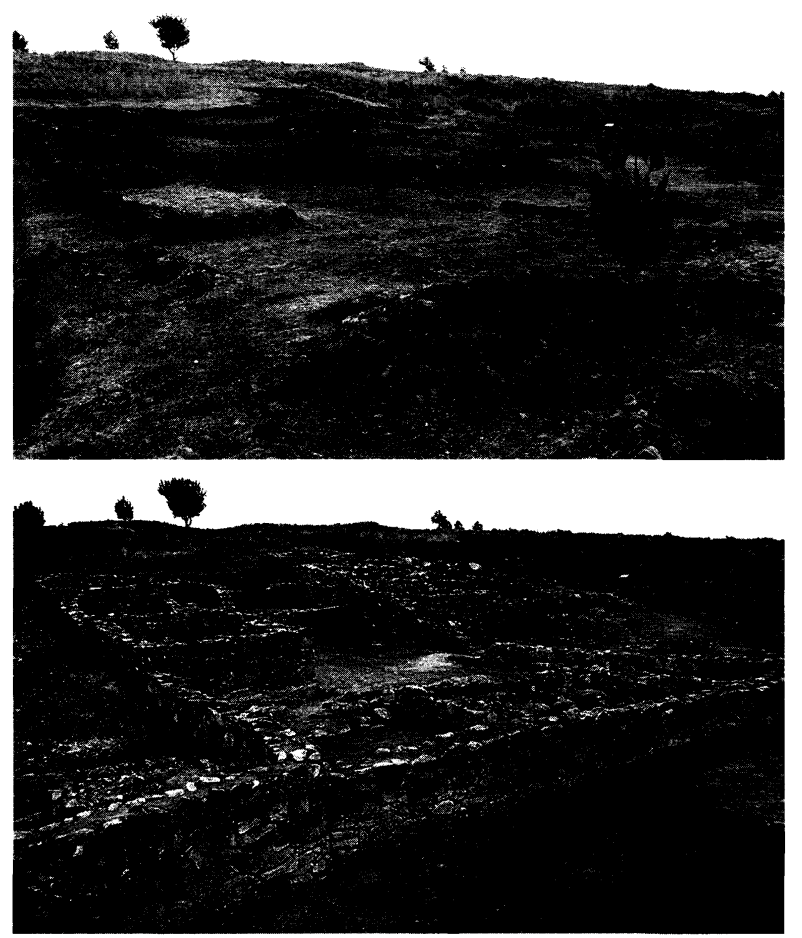

Lámina 14. Unidad familiar 5. En la foto superior vemos las estructuras excavadas en intervenciones de principios del siglo XX y en la inferior, la misma unidad familiar, una vez consolidada y restaurada. 
enderezamiento por presión del muro. Muchas veces no es posible llevar a cabo tal proceso con éxito por lo que se recurre al desmontaje del paramento.

En estos casos y como los muros se construyen a doble cara con un relleno interior de ripio y tierra, se procede a disponer cada hilada eliminada a lado de la zona marcando dos zonas de piedras ordenadas y dispuestas para ser colocadas de nuevo en su misma disposición. Este proceso de anastilosis facilita la recuperación del lienzo en la misma disposición que tenía antes del derrumbe.

Otra necesidad prioritaria de cara a la estabilización de los restos viene dada por los límites de la zona excavada. Estos son acondicionados para su perdurabilidad, para lo cual se aplican una serie de herbicidas e hidrofugantes para facilitar el drenaje. En el tema de los perfiles se trabaja de forma coordinada con los arqueólogos para que existan los menos posibles de modo que los límites de las zonas excavadas coincidan con estructuras de delimitación de barrios o unidades

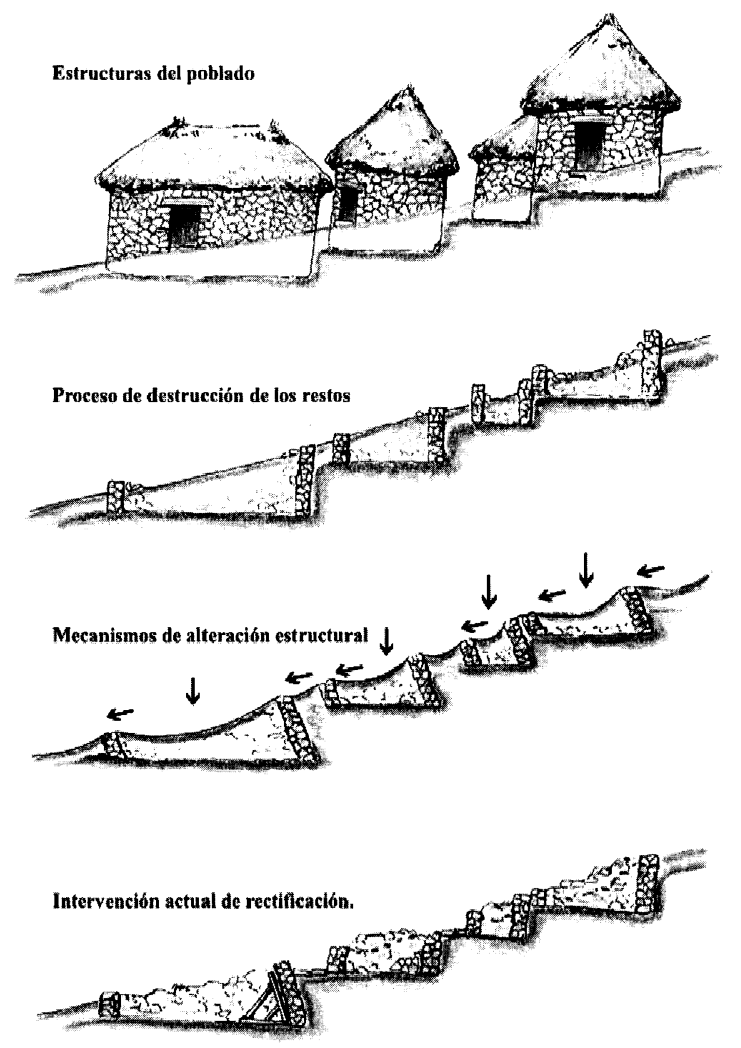

Lámina 15. 
ya que desde un punto de vista estructural, son las propias condiciones antrópicas $\mathrm{y}$ físicas del terreno las que dificultan sobremanera la posibilidad de que la consolidación de perfiles sea eficaz y duradera. Sin embargo, y como es lógico suponer, hay ocasiones en que la ausencia de estructuras y otro tipo de circunstancias, obligan a que se deba actuar sobre dichos perfiles.

Un factor de alteración no menos importante lo constituye sin duda las poblaciones de animales que hoy en día horadan el yacimiento fundamentalmente por las zonas excavadas. Son estas las que presentan una mayor accesibilidad a todo tipo de lepóridos por carecer el terreno de la dureza propia de la superficie.

Otro de los problemas como factores de alteración más común en este tipo de yacimientos es sin duda el límite de pluviosidad y la humedad en general. Todo esto dificulta en primer lugar y condiciona sobremanera la utilización de consolidantes, argamasas, etc. Los primeros deben por tanto ser compatibles con esta característica mencionada arriba. Los segundos deben poseer aditivos hidráulicos porque de lo contrario el proceso de carbonatación se puede ver afectado muy seriamente.

Por otra parte, los espacios externos de las viviendas una vez excavados funcionan en lo que respecta a la evacuación de agua del mismo modo que en la antigüedad, puesto que con esa finalidad fueron dispuestos los diferentes drenajes. El problema lo encontramos cuando nos enfrentamos ante las dependencias concebidas para estar cubiertas en las cuales no fue diseñado ningún tipo de evacuación para el agua en dichos espacios, con la necesidad de la exhibición de estas dependencias y para la comprensión de los restos propiamente dicho en la mayoría de ella es necesaria la creación de drenajes con el fin de preservar los elementos interiores.

En lo referente a los pavimentos el problema más importante de conservación está en las zonas próximas a las lagunas en las que se ha perdido el pavimento original. En estas zonas se propicia la disgregación y el aumento de tamaño de estas lagunas. Pero los pavimentos completos o mejor conservados también están expuestos a este tipo de deterioro. El agua de lluvia y la humedad procedente del sustrato sobre el que se asientan y que asciende a la superficie por capilaridad pueden producir el mismo tipo de alteración. Por ello es muy complejo y prácticamente inviable la conservación de los pavimentos a la intemperie.

Su estado de conservación es muy variado y está íntimamente ligado a la calidad de su factura, a la conservación de los paramentos verticales de las estancias en las que se sitúan y a su ubicación en el yacimiento. La pérdida de algunos paramentos ha permitido el arrastre de tierras por las lluvias lo que ha ocasionado la erosión de las argamasas y, por consiguiente, la disgregación de las zonas de los 
pavimentos situadas en las partes más bajas de la ladera. El crecimiento continuo de plantas también ha contribuido a este deterioro ya que sus raíces han ido penetrando en él influyendo también en su disgregación.

\section{Tratamiento general aplicado}

Las principales adecuaciones realizadas abarcan desde la limpieza de todo el sector del yacimiento y su área periférica, adecuación del yacimiento y de los elementos internos de las viviendas, restauración de elementos arquitectónicos y recuperación de las zonas de paso, dotación de drenajes, restitución de piezas arquitectónicas y colocación de estructuras protectoras
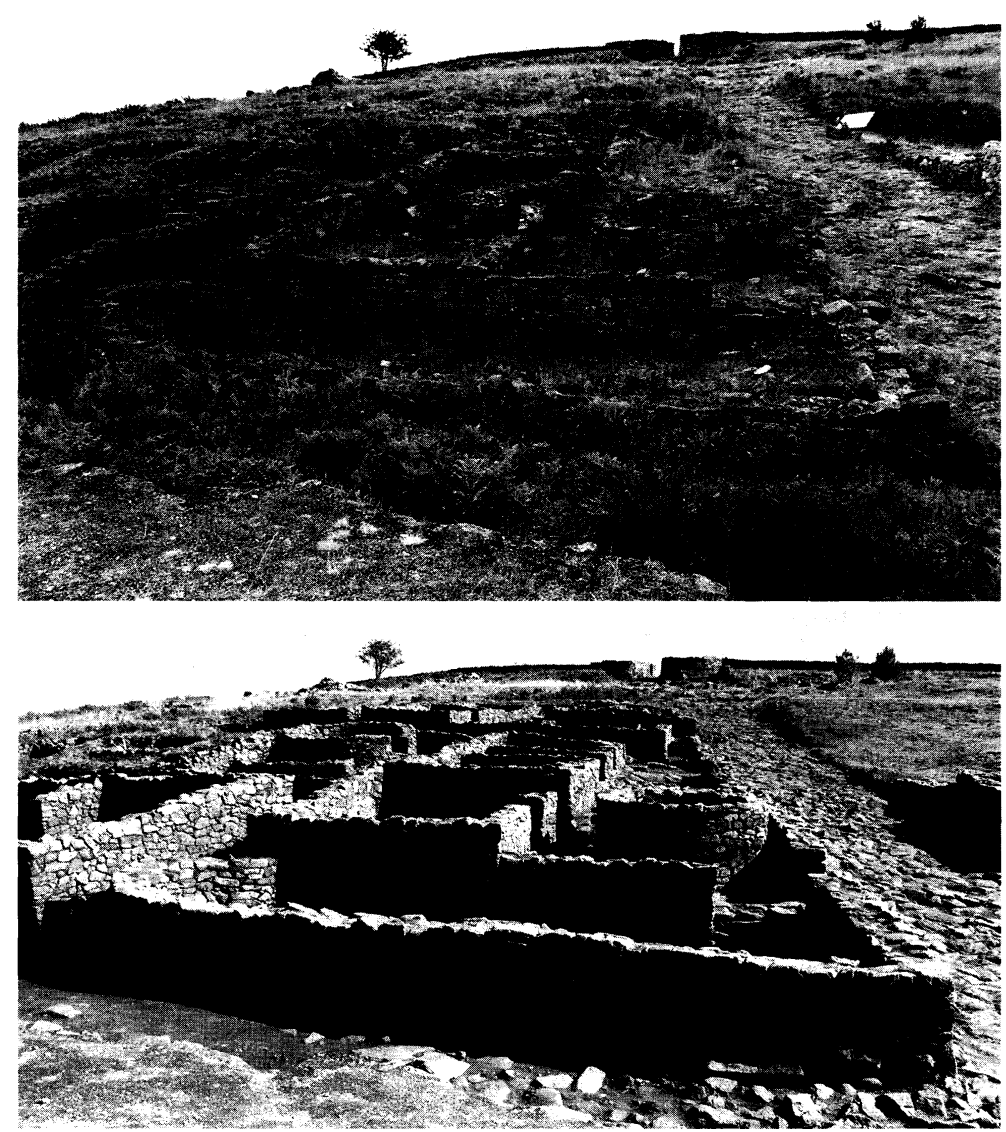

Lámina 16. Unidad familiar 7. Foto superior: Estado inicial de las estructuras excavadas a finales del siglo XX. Foto inferior: La misma unidad una vez consolidada y restaurada, vista desde la Puerta Oeste. 
La necesidad de mejorar la legibilidad de la ruina influye notablemente en la extensión de su reintegración. Se trata de lograr que el visitante comprenda mejor estas estructuras.

Como hemos dicho anteriormente la construcción de una vivienda se comienza por la estancia principal a la que se iban agregando construcciones de distinta entidad, tamaño y forma. Siguiendo este proceso, en la recuperación de volúmenes se decidió darle mayor resalte a las estancias construidas en primer lugar en detrimento de las que poseen un carácter secundario o de menor entidad, evitando también de este modo el efecto de ruina guillotinada en este espacio restaurado de grandes dimensiones.

La adhesión de estructuras no está tan relacionada con un ahorro de espacio, sino que más bien se debe al ahorro de materiales de construcción. De igual modo se aprecian distintas características de techados y vertientes hasta el punto, que en diversas ocasiones se puede precisar y llegar a reconstruir las caídas de aguas de las techumbres.

Para la restitución de hiladas en los paramentos verticales como parámetro fundamental se decidió respetar la altura de la topografía del terreno de forma que los muros no se levantan por encima de la superficie circundante. La restitución se ha

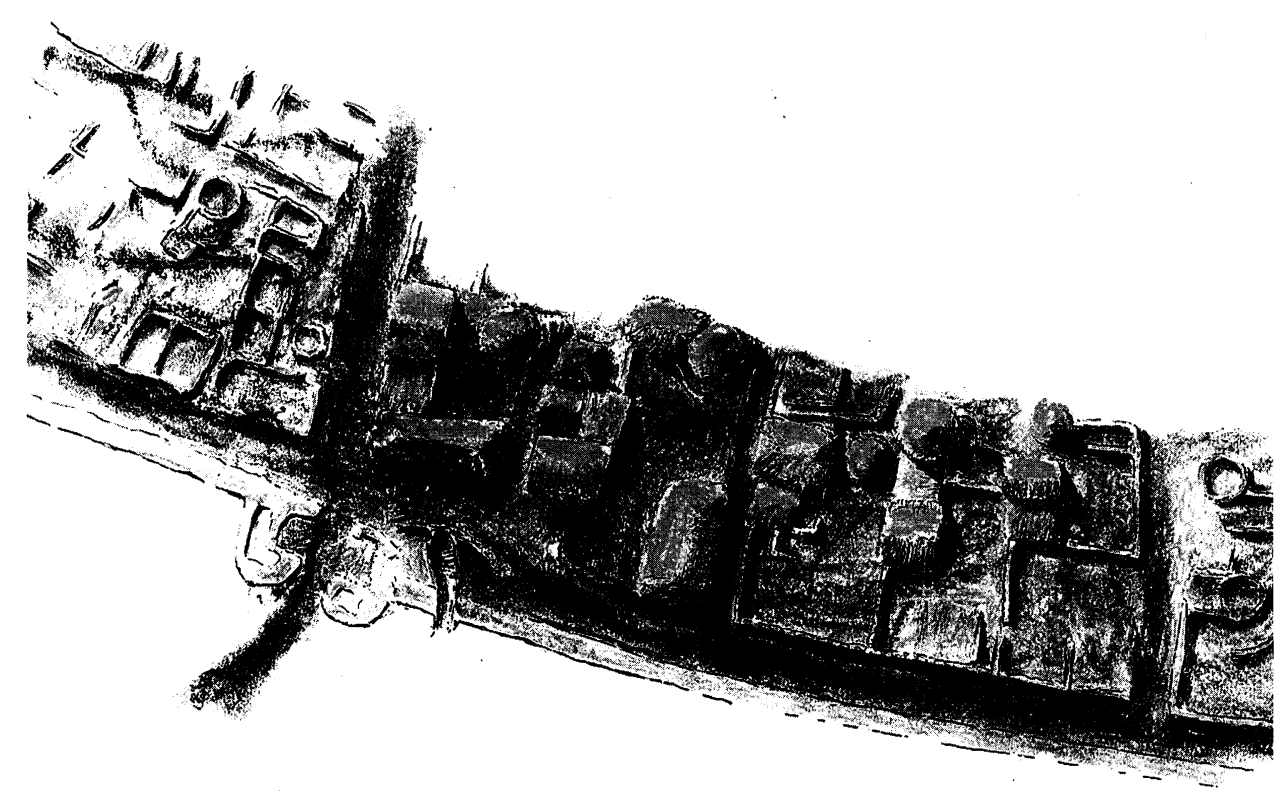

Lámina 17.- Distribución hipotética de los espacios abiertos y de las cubiertas a partir de los datos de excavación. 
realizado siguiendo el mismo carácter constructivo original: la construcción de muro a doble cara con piedra labrada poligonal formando un aparejo concertado sin descuidar la inclusión de perpiaños y recalzado con ripio.

La reposición de los elementos arquitectónicos, muros y estructuras de delimitación, se realizan por recrecida de hiladas, con el fin de proteger las originales del contacto exterior. En las nuevas hiladas se colocará el mismo tipo de piedra, incluso en paramentos de características muy específicas, la misma que se documenta en sus derrumbes durante la excavación arqueológica. (La piedra acumulada en excavaciones anteriores o la extraída en esta intervención ha sido suficiente por el momento para actuar sobre unos $3900 \mathrm{~m}^{2}$ en estas dos campañas).

Para seguir un criterio lógico de reconstrucción se ha decidido levantar en mayor altura las habitaciones que dentro de cada unidad están completamente exentas, que suelen ser las que se utilizan como zona principal de vivienda. El resto de las dependencias adosadas se recrecen en menor altura para que el volumen de los paramentos no impida la visión de la totalidad del conjunto.

Las argamasas utilizadas para el recrecimiento de los muros tienen un tratamiento que la asemeja a la original, aunque se ganará en resistencia. Sin duda alguna el mortero ideal para este tipo de actuaciones a largo plazo lo constituye el realizado a base de arena y de cal hidráulica. Su gran plasticidad y cohesión con la piedra de la zona así lo demuestran. Sin embargo la necesidad de conseguir una gran resistencia en un corto espacio de tiempo fue lo que nos inclinó por la utilización del mortero bastardo, siempre teniendo en cuenta los criterios de reversibilidad antes mencionados.

El paramento repuesto ha sido recibido con un mortero bastardo de cal y una pequeña cantidad de cemento blanco hasta llegar a un mortero M-40, a base de cal gruesa y arena de río lavada, enriquecido con algún aditivo calcinado como creta y arcilla. Este aditivo es básico para acelerar el proceso de carbonatación del mortero de cal. De otro modo y al tratarse de un yacimiento al aire libre, con una fuerte agresión antrópica y duras condiciones meteorológicas no sería posible garantizar la perduración de la intervención. La reversibilidad queda garantizada de una forma manual puesto que los llagueados no se realizan con este mortero sino que son aplicados con un proceso manual de cribado de tierras y morteros antiguos recuperados en la excavación y aglutinado con látex vinílico.

Para conseguir el tono del terreno circundante se ha tintado el mortero con colorantes de tipo inorgánico que sean insensibles a los cambios de color con altas temperaturas, criogenización, etc.

En otros yacimientos se han utilizado sistemas de reintegración a base de morteros sólo de cal, o cal hidráulica o con APV como aglutinante y han debido ser 
reemplazados por otros morteros más resistentes o que no dependan tanto de un proceso de carbonatación 9 .

El ligante o aditivo es el componente del mortero que más influye en las características finales del material. El proceso de carbonatación en el que la cal hidratada forma hidróxido cálcico y reacciona con el dióxido de carbono ambiental es la que provoca el endurecimiento del mortero. No obstante, este proceso lento, que puede durar años se ve muy influenciado por agentes atmosféricos ${ }^{10}$.

En algunos puntos concretos los muros se encuentran en muy mal estado de conservación debido a la presión de los sedimentos interiores y la erosión de la ladera que fuerza los paramentos en el sentido de la pendiente, de modo que están totalmente destruidos o vencidos con un fuerte desnivel. En estos casos, cuando el muro ha desaparecido se continúa la línea de trazado siguiendo los restos del original, en otros puntos si los paramentos se encuentran muy vencidos se procede a disponer cada hilada eliminada a lado de la zona marcando dos zonas de piedras ordenadas y dispuestas para ser colocadas de nuevo en su misma disposición. Este proceso de anastilosis facilita la recuperación del lienzo en la misma disposición que tenía antes del derrumbe y garantiza que quede completamente seguro para su perdurabilidad.

Por término medio, cada estructura posee unos $12 \mathrm{~m}^{3}$ de paramento de mampuestos y necesita aproximadamente entre 40 y 80 toneladas métricas de piedra para su restitución. En la primera campaña se movieron y colocaron 1,8 millones de kg de piedra, toda ella extraída del propio yacimiento. En la segunda campaña se han reutilizado 1,5 millones de $\mathrm{kg}$ de piedra aproximadamente para reconstruir los paramentos de aparejo concertado de encaje con una resistencia de rotura a flexión no superior a los $100 \mathrm{~kg} / \mathrm{cm}^{2}$.

Por otra parte se ha realizado una limpieza de todos los restos, área perimetral y acceso al asentamiento. Además de la limpieza del sector excavado en el cual se aplican herbicidas e hidrofugantes, se realizó una limpieza de la vegetación en todo el sector perimetral y de toda la zona de acceso, la cual se acondicionó convenientemente. Por otra parte se procedió a la retirada de la escombrera y amontonamientos de piedra de campañas de excavación previas, con el fin de dejar en su estado original todo el sector Oeste del asentamiento a la vez que se reutilizó buena parte de esa materia prima original para el recrecimiento de los muros.

\footnotetext{
${ }^{9}$ En otros casos sin embargo, el APV ha resultado como aditivo óptimo hasta llegar a la carbonatación de la cal, tal vez la agresión antrópica sea menor.

${ }^{10}$ Sobre todo frío y humedad que retardan la cinética de la reacción, (Sauman, 1972).
} 

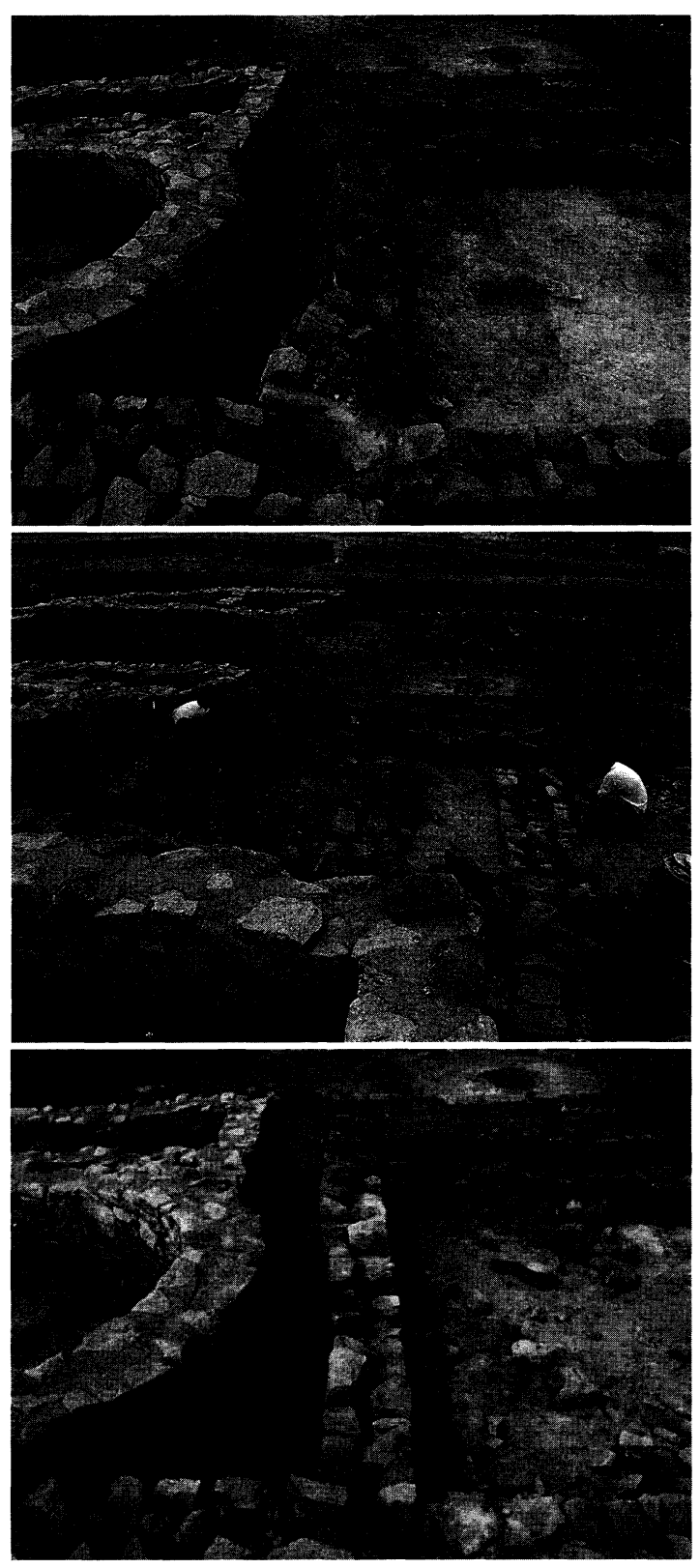

Lámina 18. Proceso de anastilosis. Arriba: Se desmonta el lienzo del muro afectado de una forma ordenada, siguiendo su disposición, para luego devolverlas a su emplazamiento original; facilita la recuperación del lienzo y garantiza su perdurabilidad. Medio: Situación de la estructura antes del proceso de consolidación. Abajo: La estructura finalizado el proceso de anastafilosis. 

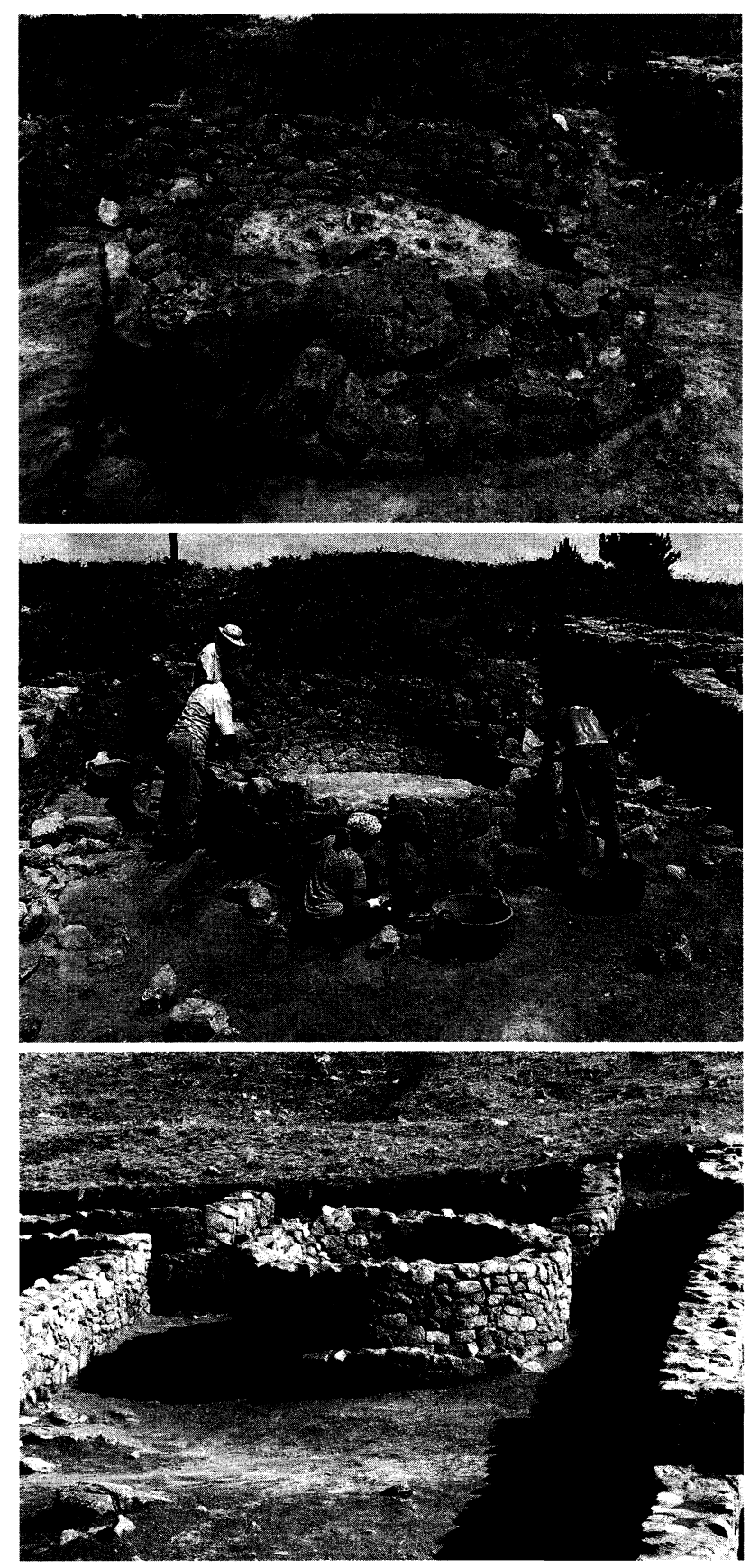

Lámina 19.- Proceso de restauración de una dependencia dedicada a almacén.

Cuadernos de Estudios Gallegos, Tomo LI, Fascículo 117, Santiago 2004. (Págs. 79 - 113) 
La solución para la estabilización y conservación de cortes estratigráficos, de la excavación fundamentalmente viene dado por los límites de la zona excavada. Son acondicionados para su perdurabilidad, para lo cual se aplican una serie de herbicidas e hidrofugantes como Tegovisin o Rember para facilitar el drenaje, se refuerzan puntualmente los en lugares más problemáticos Por otra parte para evitar su derrumbe se perfilan en talud con una ligera inclinación de $60^{\circ}$, esto refuerza los taludes evitando el arrastre de las tierras por el agua de lluvia. De todos modos como ya hemos apuntado, se trabaja de forma coordinada con los arqueólogos para que exista el menor número posible de ellos de modo que los límites de las zonas excavadas coincidan con estructuras de delimitación de los barrios o unidades familiares.

Respecto a la recuperación de los pavimentos y zonas de paso podríamos apuntar una diferenciación entre los construidos con sabrego y las zonas empedradas. Los pavimentos de tierra son constituidos generalmente por una mezcla de sabrego y cal apisonada sobre una base de ripio en toda la superficie del piso de la estancia que ocupa. En ocasiones este preparado se extiende y es apisonado sobre el zócalo de las estructuras que lo delimitan. Respecto a las zonas empedradas se realizan a base de piedras planas con superficies lisas de diversos tamaños colocadas a modo de mosaico sobre una base de tierra o argamasa.

Se reintegraron las zonas que estaban perdidas en los pavimentos que se conservaban, tanto en las viviendas como en las zonas de paso y se consolidaron los que se encontraban en buenas condiciones, utilizando en todos los casos los mismos materiales que los originales, manteniendo la premisa de utilizar el mismo elemento diferenciador que en los paramentos, la pizarra.

Para la recuperación y conservación de los pavimentos de tierra se aplicó el siguiente tratamiento: en primer lugar se realiza una limpieza de tierra y se eliminan los biofitos y posteriormente se procede a la restitución de las lagunas o faltas del conjunto mediante la aplicación de un mortero de cal y tintado para conseguir una tonalidad ligeramente distinta a la del pavimento original. En las zonas de contacto entre la argamasa y el pavimento se aplicó un elemento diferenciador a base de polietileno. Una vez seco se aplican herbicidas de tipo hormonal sobre la superficie, con efecto residual y acción fungicida.

Otro tipo de tratamiento con carácter protector y a la vez didáctico se realiza sobre aquellos pavimentos de tierra cuya cohesión estructural es muy débil y sufren un elevado riesgo de degradación debido a su ubicación. Este consiste en la fabricación de una réplica del pavimento sobre el original sobre una capa de intervención que separa la réplica del original garantizando su reversibilidad.

En las zonas empedradas el único tratamiento aparte de la limpieza y la aplicación de herbicidas ha sido la restitución de las lajas que se habían perdido por otras 
de iguales características colocadas sobre arcosas y arcilla y diferenciadas de las originales por la inclusión de elementos diferenciadores (pizarra serrada).

La reposición de las zonas de acceso contribuye a la consolidación de algunas estructuras y facilita la lectura que el visitante pueda hacer del yacimiento. Algunos de los tratamientos propuestos anteriormente aúnan la conservación y la restauración de ciertas estructuras conformando ciertos volúmenes entendibles. A modo muy excepcional nos vimos obligados a la restitución de algunos elementos constructivos con el único objeto de contribuir a recrear estructuras incompletas o totalmente perdidas como parte de una escenografía didáctica montada en el propio yacimiento.

En muchas de las habitaciones se conocen los accesos originales, y éstos se han reconstruido exactamente en el mismo lugar donde se encontraron, sin embargo en algunos casos el deterioro del muro ha llegado a la parte inferior y los vanos de acceso se desconocen por lo que procedemos a abrir un vano irregular en el muro en la zona de acceso más lógica según se distribuyen los espacios dentro de cada unidad. Únicamente en casos muy concretos en los que prácticamente se tenía la certeza de su ubicación se procedió a la restitución de umbrales con el fin de recrear ciertas construcciones. No se puede hablar de reintegración puesto que no se trata de completar elementos fragmentados; se trata de la reposición de elementos perdidos con la intención de mejorar la interpretación visual del yacimiento y de contribuir al refuerzo de ciertas estructuras.

\section{Elementos estructurales de protección con carácter didáctico}

En cuanto a las estructuras documentadas en el interior de las viviendas mencionadas, restos de elementos interiores, bancos, hogares, etc., se procede únicamente a su limpieza, aunque en la mayoría de los casos sufre un segundo tratamiento; consolidación y reintegración, y excepcionalmente se propone la construcción de una réplica encima del original. Del mismo modo que se ha procedido en los pavimentos se ha realizado la reposición de ciertos elementos de las estructuras interiores de las casas con doble finalidad; resistencia y didáctica. Prácticamente se reducen a algunas lajas de hogares y hornos, o reposiciones muy puntuales de morteros de granito recientemente sustraídos.

Como tratamiento de inicio se procede a una primera limpieza y estabilización de las estructuras internas, hornos, poyetes, bancos, parrillas u hogares, que a su vez se protegieron durante todas las labores de reconstrucción de los paramentos.

En general estos elementos se encuentran en malas condiciones de conservación ya que han sufrido múltiples agresiones al estar expuestos a todo tipo de agentes de alteraciỏn; antrópicos, ambientales, biológicos, etc. 
En el caso concreto de los hogares tras finalizar la restitución de los paramentos de la estancia correspondiente se procede a una nueva limpieza de los mismos, para a continuación acometer su consolidación mediante la aplicación de hidrofugantes y resinas acrílicas. Seguidamente en los casos que presenten cierta perdida de masa o fisuras considerables se procede a su restitución o rellenado por medio de la aplicación de morteros hidrofugados con aditivos tintados con pigmentos inorgánicos. Las zonas de contacto entre original y repuesto se cubrieron con un elemento diferenciador a base de polietilenos.

Como hemos dicho en casos excepcionales, fundamentalmente por motivos de protección y con una finalidad claramente didáctica se ha realizado la reproducción de los mismos encima de los originales. De igual modo algunos elementos muebles asociados a las cocinas como los morteros de granito que han sido sustraídos o arrancados en intervenciones anteriores han sido respuestas y fijados al pavimento.

Respecto a los enlucidos murales la mayor parte de ellos han sido lavados y se encuentran depositados en forma de sedimento sobre el pavimento de algunas estancias. Los pocos restos que se conservan in situ se hayan muy deteriorados y en su mayor parte han perdido la superficie original y presentan muy poca adherencia. Dado la escasa información que nos ofrece su estado original, por el momento no son susceptibles de ser restaurados con fiabilidad interpretativa, por lo que nos hemos limitado a la toma de muestras de los restos.

Como decíamos al comienzo del texto, estas dos campañas de intervenciones arqueológicas en el Castro de San Cibrán de Lás constituyen el comienzo de un proyecto mucho más ambicioso, que tiene como objetivo la puesta en valor del yacimiento y su entorno de cara a su divulgación, no sólo a través de la visita al castro sino que partiendo de la creación del Centro de Interpretación de la Cultura Castreña (que se haya en construcción) podrán conocerse todos los aspectos de esta cultura. Este centro formará parte de la Red de Patrimonio Gallego, cuyo objetivo es la gestión, protección y difusión de todo el patrimonio de la comunidad de Galicia.

La puesta en marcha de este plan de intervención ha supuesto la implicación de un gran equipo de profesionales que durante varios meses y con la ayuda de numerosa mano de obra procedente de las localidades del entorno ha aplicado toda su experiencia para la buena marcha de los trabajos.

Las nuevas excavaciones han permitido una mayor definición de la estructura del poblado, aunque estos primeros resultados deberán ser contrastados con nuevas investigaciones tanto en otras zonas del propio yacimiento como en otros asentamientos del entorno. 
Respecto a la restauración de las estructuras, el tratamiento aplicado además de novedoso por el hecho de estar combinado con los trabajos de excavación ha permitido la recuperación de unos restos que se encontraban en un estado de deterioro constante y además de su protección se ha conseguido adecuarlos para su puesta en valor con el fin de que sea posible la interpretación de los mismos.

\section{BIBLIOGRAFÍA}

BINDA, L. 1984. «Measurement of the resistance to deterioration of old and new bricks». Durability of buildings materials, $2, \mathrm{n}^{\circ} 2$.

CARRERA y BARBI. 1990. La consolidación de yacimientos arqueológicos: El castro de Fazouro, Lugo. VII Congreso de Conservación de Bienes Culturales, Valencia.

CHAMOSO LAMAS, M. Excavaciones arqueológicas en San Cibrán de Lás (Orense), Cuadernos de Estudios Gallegos. IX, Santiago, 1954. (406-410).

CHAMOSO LAMAS, M. Excavaciones arqueológicas en la citania de San Cibrán de Lás y en el poblado y explotación minera de oro de época romana de Barbantes (Orense). Noticiario Arqueológico Hispánico, III-IV (1953-1954), Madrid, 1956. (114-130).

FARIÑA BUSTO, F. e FERNÁNDEZ BAL, M.L. A «Cidade» de San Cibrán de Lás (San AmaroPunxín, Ourense). Arqueología-Informes. Campaña 1987. Xunta de Galicia, Santiago, 1989. (74-76).

FARIÑA BUSTO, F. e FERNÁNDEZ BAL, M.L. A Cidade de San Cibrán de Lás. ArqueologíaInformes, 1. Campaña 1988. Xunta de Galicia, Santiago, 1989. (209-213).

GARCIA MURILLO y MARTÍN. 1996. «Los organismos vivos como factores que contribuyen al deterioro de nuestros monumentos». BIAPH, $\mathrm{n}^{\circ} 14$.

LÓPEZ CUEVILLAS, F. O castro de A Cibdade de San Ciprián de Lás, NÓS, no 10 (18-21), 12 (1113) e 13 (12-14). Ourense. 1922.

LÓPEZ CUEVILlaS, F. A citania do monte A Cidade en San Ciprián de Lás. Boletín de la Real Academia Gallega, XIV, 1923-24 (201-206, 227-232, 250-257, 301-305) e XV, 1925-26 (7-13).

LÓPEZ CUEVILLAS, F. A citania do monte A Cibdade en San Cibrao das Lás. Boletín de la Real Academia Gallega, XVII, 1927-28 (1-9 e 51-57).

MARTA, R. 1986. Técnica constructiva romana. Editorial Kappa, pp. 9-51.

PÉREZ OUTEIRIÑO, B. Informe sobre las excavaciones arqueológicas de A Cidade de San Cibrán de Läs (San Amaro-Punxín. Ourense).Noticiario Arqueológico Hispánico, 22. Madrid, 1985. (211-259).

PÉREZ OUTEIRIÑO, B. Un singular resto arquitectónico en A Cidade de San Cibrán de Lás (San Amaro-Punxín. Ourense), Portugalia. Nova Sèrie, VI/VII. Porto, 1985/86. (29-40).

PÉREZ OUTEIRIÑO, B. A Cidade de San Cibrán de Lás. Objetivos e resultados das últimas intervencións arqueolóxicas, Lucerna, Segunda série II, Porto, 1987. (15-39).

Cuadernos de Estudios Gallegos, Tomo LI, Fascículo 117, Santiago 2004. (Págs. 79 - 113) 
SAMEÑO, M. y ROWE, J. 1994. «Biodeterioro y alteración biológica de monumentos». BIAPH, $\mathrm{n}^{\circ} 10$, pp. 26-28.

SAUMAN, Z. 1972. "Effect of carbon dioxide on porous concrete». Cem. Concr. Res., $\mathrm{n}^{\circ} 2$, pp. 541-549.

XUSTO RODRÍGUEZ, M., RODRÍGUEZ CAO, C. e FARIÑA BUSTO, F. A Cidade. San Cibrán de Lás.Ourense, 1992.

XUSTO RODRÍGUEZ, M., RODRÍGUEZ CAO, C. e FARIÑA BUSTO, F. San Cibrán de Lás. A Cidade. Guías do Patrimonio Cultural, 4, Ourense, 1992. 